\title{
Smart materials-integrated sensor technologies for COVID-19 diagnosis
}

\author{
Özgecan Erdem ${ }^{1} \cdot$ Esma Derin $^{1,2} \cdot$ Kutay Sagdic $^{1,2} \cdot$ Eylul Gulsen Yilmaz ${ }^{1,2} \cdot$ Fatih Inci $^{1,2}$
}

Received: 15 October 2020 / Accepted: 1 December 2020 / Published online: 21 January 2021

(C) Qatar University and Springer Nature Switzerland AG 2021

\begin{abstract}
After the first case has appeared in China, the COVID-19 pandemic continues to pose an omnipresent threat to global health, affecting more than 70 million patients and leading to around 1.6 million deaths. To implement rapid and effective clinical management, early diagnosis is the mainstay. Today, real-time reverse transcriptase (RT)-PCR test is the major diagnostic practice as a gold standard method for accurate diagnosis of this disease. On the other side, serological assays are easy to be implemented for the disease screening. Considering the limitations of today's tests including lengthy assay time, cost, the need for skilled personnel, and specialized infrastructure, both strategies, however, have impediments to be applied to the resource-scarce settings. Therefore, there is an urgent need to democratize all these practices to be applicable across the globe, specifically to the locations comprising of very limited infrastructure. In this regard, sensor systems have been utilized in clinical diagnostics largely, holding great potential to have pivotal roles as an alternative or complementary options to these current tests, providing crucial fashions such as being suitable for point-of-care settings, cost-effective, and having short turnover time. In particular, the integration of smart materials into sensor technologies leverages their analytical performances, including sensitivity, linear dynamic range, and specificity. Herein, we comprehensively review major smart materials such as nanomaterials, photosensitive materials, electrically sensitive materials, their integration with sensor platforms, and applications as wearable tools within the scope of the COVID-19 diagnosis.
\end{abstract}

Keywords Smart materials $\cdot$ Sensors $\cdot$ Diagnostics $\cdot$ COVID-19 $\cdot$ Point-of-care

\section{Introduction}

Virus infections hold remarkable impact over human health, including mild illnesses such as common cold [1], influenza [2], smallpox [3] and more severe even lethal diseases, for instance, rabies [4], Ebola [5], AIDS [6], hepatitis [7], avian influenza [8], SARS [9], and MERS [9]. Most recently, we have experienced another severe disease, i.e., coronavirus disease 2019 (COVID-19) [9]. Within one and half decades, people have faced five different pandemics caused by viral infections, i.e., severe acute respiratory syndrome (SARS), Swine flu, Ebola, Middle East respiratory syndrome (MERS), and COVID-19 [10]. To curb these pandemics, early

Özgecan Erdem and Esma Derin contributed equally to this work.

Fatih Inci

finci@bilkent.edu.tr

UNAM-National Nanotechnology Research Center, Bilkent

University, 06800 Ankara, Turkey diagnosis is the key step to initiate the most effective therapy and also, to manage the spread of infections [11, 12]. Enzymelinked immunosorbent test (ELISA) [13], RT-PCR [14], polymerase chain reaction (PCR) [15], and a variety of biosensor [16] are employed to detect viruses. Virus detection platforms reliant on antigen-antibody or receptor-ligand-based are also available to the point-of-need settings $[17,18]$. However, disparities across the globe impede to reach minimally required resources for testing, thereby leading to high risk of mortality and massive economic burden in resource-scarce areas. In particularly, COVID-19 holds a massive socio-economic burden and it is now stated as "\$16 Trillion Disease" [19] that cannot be limited to the resource-constrained settings only,

2 Institute of Materials Science and Nanotechnology, Bilkent University, 06800 Ankara, Turkey 
and it has to be expanded to the global level. The World Health Organization (WHO) and other governmental institutions are hence alarming to accelerate the expansion of testing everywhere, but gold standard methods, i.e., PCR-stemmed tests, have logistic and utility limitations while applying them to low-resource settings. Nevertheless, serological assays enable easy-to-use and low-cost fashions, they are prone to falsepositive results. In regard to these facts, developing biosensor platforms for both point-of-care (POC) and clinical settings provides one of the ultimate goals in the COVID-19 pandemic to expedite diagnostic procedure, potentially allowing to control the disease at the most efficient social and economic measures [11, 20-22].

The expeditious advances in nanotechnology have led enormous impact in science and technology through the development of innovative and diverse nanoscale materials, harmonizing unique optical, electrical, magnetic, or catalytic properties for the production of biosensors [23, 24]. Smart materials are majorly considered as a class of nanomaterials, providing their key responses (e.g., color, shape, rigidity, opacity, or porosity) to stimuli applied $[25,26]$. The integration of the smart materials with biosensor platforms potentially enables to enhance sensitivity and it also provides more specificity and label-free manners with unique designs of materials [27]. Hitherto, from a virus diagnostic perspective, the literature has a variety of strategies comprising of distinct bioelements (CRISPR-Cas9 [28], nucleic acids [29], aptamers [30]), materials/transducers (nanoparticles [31, 32], electrochemical, optical [33]), and integrative platforms such as microfluidics [34]. During this pandemic, these tools would provide effective, rapid, reliable, easy-to-use, and portable schemes [35]. In this review, we elaborate the fundamentals on the COVID-19 diagnosis, and provide a comprehensive literature on smart materials (e.g., graphene, light sensitive, electrically sensitive, and wearable intelligent materials) and their biosensor integrations with the examples of virus detection including SARS-CoV-2.

\section{COVID-19 outbreak}

In December 2019, after three adult patients admitted to a hospital in Wuhan with severe pneumonia, meticulous studies revealed that the common point of these three people was their presence in the seafood market. After these suspecting situations, clinical examinations were associated with a new coronavirus [36]. After the novel Coronavirus ( $\mathrm{CoV})$ outbreak was reported in Wuhan, China, in December 2019, the infection began to spread rapidly to China and other countries of the world [37]. In February 2020, the WHO announced the COVID-19 pandemic with the causative agent of SARS$\mathrm{CoV}-2$. Basically, coronaviruses are one of the leading pathogens that mainly target the human respiratory system [38], and the members of this family are enveloped, RNA viruses that can cause infection on humans and a variety of animals [39]. In the last two decades before this pandemic, the world has faced two different cases of CoVs. One of them was caused by SARS-CoV, resulted in nearly 8000 cases and 800 deaths, whereas the latter was MERS-CoV causing Middle East respiratory syndrome, leading to approximately 2500 cases and again around 800 deaths [40]. Consequently, the COVID-19 has progressive statistics, affecting more than 30 million people and resulting in $\sim 1$ million deaths across 213 countries worldwide, and thereby, it has to be taken more seriously than the earlier ones [41]. Briefly, SARS-CoV-2 is transmitted from person-to-person through droplets, contact, and contaminated objects. Indirect or direct contacts with mucous membranes in mouth, eyes, or nose are vulnerable to virus infection [36, 42]. Typical symptoms of COVID-19 are listed as fever, sore throat, tiredness, cough, and shortness of breath. Data demonstrating the early transmission dynamics of COVID-19 revealed 5.2 days of an average incubation time, and then this information was updated as 6.4 days with new studies [43]. On the other side, patients, who are asymptomatic and unaware of their COVID-19 status are currently in the society, causing the vast majority of transmission. Persons, who stay without any symptoms during the disease period are called "asymptomatic," and those, who are in the early stages of the disease after the infection has occurred but whose symptoms have not yet developed are called "presymptomatic." The presymptomatic phase, an unusual feature for respiratory tract infection, might be one of the most contagious phases $[44,45]$.

To curb the COVID-19 pandemic, many countries have started to take the necessary measures, such as very limited entry and exit at the borders, the use of protective equipment, rescheduling/postponing schools or any public organization, and local quarantines that form our "new normal" in daily life [46]. As projected, the major damaging effects of this pandemic would be reduced with such actions until a vaccine and any specific/repurposed drug was developed against the COVID-19. In previous $\mathrm{CoV}$ outbreaks, there were various difficulties in developing the vaccine. Generally, vaccines showing immunogenic effects in animal models did not effectively prevent the acquisition of the disease. Apart from this, vaccination would not induce long-lasting immunity as observed in the early cases, implying a risk of re-infection [47, 48]. As of September 2020 , there are currently 34 vaccine candidates that have reached to phase 3 , and 142 vaccine candidates at the preclinical stage, which are being developed for the prevention of COVID-19 [49]. As of December 2020, PfizerBioNTech, Moderna, Oxford-AstraZeneca, and Gamaleya (Sputnik V) have declared RNA-based and viral vectorbased vaccines, the most remarkable steps in the recent literature of COVID-19. 


\section{Current diagnostic strategies}

Early and rapid detection of a disease is pivotal for an accurate clinical management. Specific to SARS-CoV-2 infection, within 5 to 6 days after the onset of symptoms, patients show a high viral load on their nasopharyngeal or oropharyngeal areas [50]. In practice, diagnostic assays reliant on nucleic acid detection, especially Polymerase Chain Reaction (PCR)-based systems, are considered as the gold standard method. These assays include reverse transcription PCR (RT-PCR), real-time RT-PCR (rRT $\mathrm{PCR}$ ), and reverse transcription loop-mediated isothermal amplification (RT - LAMP), requiring specific primers and probes to SARS-CoV-2 genes, coding the first open reading frames [51], RNA-dependent RNA polymerase [52], envelope proteins [53], and nucleocapsids [54]. As faced during the pandemic, sampling errors, primer/probe designs, and RNA isolation are still impeding the assay performance and accuracy. For instance, although a negative RT-PCR result is obtained in some cases, chest computerized tomography is needed for persons with symptoms [43]. The RT-PCR tests would be complemented by imaging platforms and the other clinical tests, therefore facilitating an easy control of the pandemic [55].

In addition to RT-PCR tests, serological assays using virus antigen or virus-specific antibodies are alternative tests since they have a short turnaround time, facile sampling, and easyto use features [56]. These tests also provide a low-cost opportunity in the diagnosis of acute infection and they can be applied to the POC settings easily. Another important advantage of these tests over the RT-PCR is to distinguish patients, who have had COVID-19 before, even if they have never been tested while they were in the acute phase [57]. Commonly used serological assays for SARS-CoV-2 include ELISA [58], lateral flow assays (LFAs) [59], and virus neutralization assays [60]. These tests mainly focus to detect the spike protein of SARS-CoV-2, the receptor binding domain (a part of the spike protein) or viral nucleoproteins [61]. Although serological assays have utility to actively identify close contacts for rapid identification and subsequent events [62], they are prone to false-positive results, and mostly cannot provide information on the viral load levels of persons.

\section{Smart materials for sensor technologies}

Characteristics of smart materials can be explained by the capability of sensing and responding to one or more than one stimulus reversibly. When the stimuli are removed, they turn their original states $[63,64]$. These stimuli can be either external (e.g., environmental stimuli) or internal stimuli including chemical (i.e., $\mathrm{pH}$, ionic strength), electrical, light, temperature, magnetic, and mechanical stimuli. [63, 64]. The usage of the smart materials is not restricted to sensor technology, and their applications range from actuators, robotics to artificial muscles, controlled drug delivery systems, and tissue engineering [63, 64]. In regard to diverse applications, smart material development intersects at multi-disciplines spanning from materials science, chemistry, physics, engineering, and nanotechnology.

Touching upon the smart materials, common materials include ionic and magnetic responsive materials, light, electrical, enzyme, temperature, $\mathrm{pH}$ and sensitive, and enzymatic reaction sensitive materials [26]. Particularly, polymeric substances hold great potential to be deployed into living systems, owing to good flexibility, light weight, mass-producibility, and high transparency. However, their mechanical strength and stability are low. On the contrary, carbon-based nanomaterials provide mechanically strong and flexible, electrically and thermally conductive assets in addition to biocompatibility and antiviral properties [20,63]. Considering electroanalytical performance and immobilization of recognition elements, current biosensor platforms mostly integrates diverse nanomaterials $[65,66]$ stemmed from carbonaceous materials (e.g., carbon nanotubes [67], graphene [68-71], carbon nanoparticles [72]), inorganic materials (e.g., magnetic and metal nanoparticles [73]), organic nanoparticles (e.g., dendrimers [74]) conductive and insulating polymers (e.g., nanosized and nanostructured polymers or molecularly imprinted polymers [75]), and hybrid materials (e.g., hydrogel [76]). By integrating these materials with biosensors, high selectivity, high sensitivity, rapid response time, easy-to-use, cost-effective features are aimed. For instance, cantilevers [77], nanotubes [67], ferromagnetic particles [78], conducting films and gels [75], dendrimers [74], microspheres [79] and nanoparticles [80] are only some examples in this domain.

\subsection{Nanomaterials}

\subsubsection{Graphene-polymer systems}

Nanomaterials (NMs), a.k.a. nanostructured materials, are described as a material, whose structure size is at the nanoscale (e.g., $100 \mathrm{~nm}$ or even less) with the ability of controllability on structure to achieve the desired behavior and to integrate with the designed devices [81, 82]. This definition can also be extended to a particle, having at least one dimension at a nanoscale to gain novel and specialized properties, such as high surface-volume ratio, easy derivatization, and exclusive thermal, mechanical, or electronic properties [83]. The preparation of NMs consists of diverse methodology, including cutting, ball-milling, extruding, chipping, and pounding addition to bottom-up and top-down approaches [84]. Specifically, top-down approaches utilize bulk materials to turn into nanomaterial, whereas bottom-up approaches use finer scale to build up nanomaterial [81]. NMs are classified majorly according to their physical and chemical properties, origin (e.g., natural, rational designed or synthesized etc.), dimension 
(e.g., 0D, 1D, 2D and 3D), and composition (e.g., carbon, inorganic, organic and composite based NMs) [82, 84]. Except this majority, nanoparticles (NPs) are mostly classified on their morphology, dimensionality, and uniformity [84].

Carbon-based NMs constitute a large section of the NM family and the wide variety in their physicochemical properties enables their implementations to many different applications [11]. Diverse shape and dimensional carbon-based NMs can be derived as nanodiamonds, fullerenes, carbon nanotubes, graphene, carbon nanofibers, carbon nanocones-disks, and nanohorns. They interact with the organic molecules easily due to non-covalent forces (e.g., hydrogen bonding, stacking, electrostatic forces, van der Waals forces, and hydrophobic interactions) [83]. NMs are the result of the splendid advances in nanotechnology; therefore, their conjugation is executed majorly. For instance, in the biosensor fabrication, they are mostly employed to coat metallic nanomaterials, silica NPs, dendrimers, quantum dots (QDs), polymer NPs, carbon nanotubes (CNTs), nanodiamonds (NDs), and 2Dnanomaterials (e.g., graphene, hexagonal boron nitride (h$\mathrm{BN}$ ), niobium selenide, molybdenum disulfide, and tungsten disulfide) [27]. Among different NMs, graphene has been garnered remarkable interest since it represents unique physicochemical properties, extremely high electrical and thermal conductivity, optical properties, biocompatibility, ease-offunctionalization, strength and flexibility, and chemical stability $[11,27]$. The structure of graphene is constituted by covalently bonds of $\mathrm{sp}^{2}$ carbon atoms to form $2 \mathrm{D}$ and atomically thin layer in honeycomb lattice $[11,85]$, thereby ultimately displaying unique electronic properties since they are semimetal/zero-gap semiconductor due to association of their valence and conductive bands with Dirac points. Thanks to all these properties, graphene can take place in wide variety application from mechanical reinforcement to sensing [11]. In the beginning, the production was carried out by mechanical exfoliation of graphite, yet this method is not efficient and cannot provide reproducible production. High-quality graphene films are achieved via epitaxial growth and chemical vapor deposition (CVD) techniques. Solution-processable graphene is commonly attained via oxidization and reduction of graphite, respectively. Treating graphene to graphene oxide (GO) and reduced graphene oxide (rGO) supply abundant oxygen containing groups, which mediate an enhancement in stimuli-responsive behavior in aqueous solution. The common fabrication methods of GO are blade-coating, solvent evaporation, vacuum filtration, spin-coating, or dip-coating, and their performance is boosted via additional photochemical treatments, such as laser, solar, or UV irradiation. The rGO is obtained through thermal or chemical reduction of GO [63].

Graphene-based biosensor systems are developed by taking advantages of different sensing mechanisms, such as fieldeffect transistor (FET), optical, electrochemical, and microfluidics. In addition, their surfaces are modified with a wide range of chemical approaches, including amino silane, carboxy, diazonium, and plasma chemistry to immobilize biorecognition element for the determination of various kinds of pathogens [27]. Graphene has diverse applications in biosensors to detect various types of infections, which can be either viruses (e.g., Zika [86], influenza (H1N1) [70], avian influenza (H7) [32], Ebola [87], papillomavirus [71], SARSCoV-2 [68]), or bacteria (e.g., Vibrio parahaemolyticus [88]) or other pathogenic entities. For the detection of the Zika, leading to severe brain defects in fetuses and consequently resulting in Guillain Barre Syndrome in adults in long-terms, a graphene biosensor achieved real-time and quantitative detection of native Zika viral antigens (ZIKV NS1) [86]. The basic representation of sensor design was summarized in Fig. 1. Capacitance changes corresponding to antigen concentrations were measured, and the sensor revealed a detection limit down to $450 \mathrm{pM}$ of ZIKV NS1 in buffer solutions. Another recent study also depicted a graphene-based electrochemical biosensor for the detection of Zika viruses. As summarized in Fig. 2a, surface imprinted polymers (SIPs)—specific molecular cavities recognizing target molecules, were decorated on graphene oxide composites. The alterations in electrochemical signals were measured as the sensor response, which provided comparable results with real-time quantitative reverse transcription PCR method [89]. In another study, the lipid bilayer of feline coronavirus was absorbed by GO and rGO via hydrogen bonding and electrostatic interactions, which lead to viral membrane destruction, holding great potential on both detection and prevention of COVID-19 [90]. In addition to graphene-type sensors, NPs and graphene-integrated nanocomposites were also adapted as an alternative method for the detection and quantification of influenza virus H7 [90]. Briefly, gold nanoparticles (AuNPs) and graphene nanocomposites decorated on electrode and silver nanoparticles (AgNPs) were employed
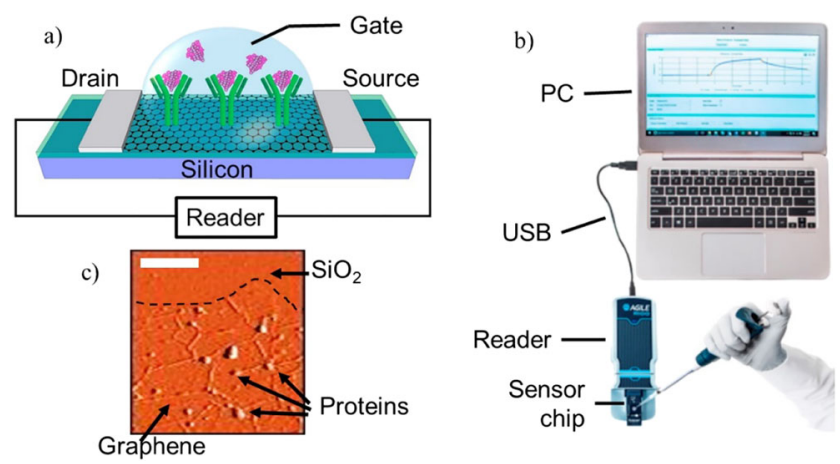

Fig. 1 A graphene-based biosensor for the detection of Zika virus. a Illustration of the sensor elements. b The entire sensor platform comprising of a reader, digital control, PC running control, and software. c AFM view of graphene surface of the sensor, where the proteins were captured (scale bar is $1 \mu \mathrm{m}$ ). Copyright permission for reuse from the ref. [86] 
$\mathbf{a}$

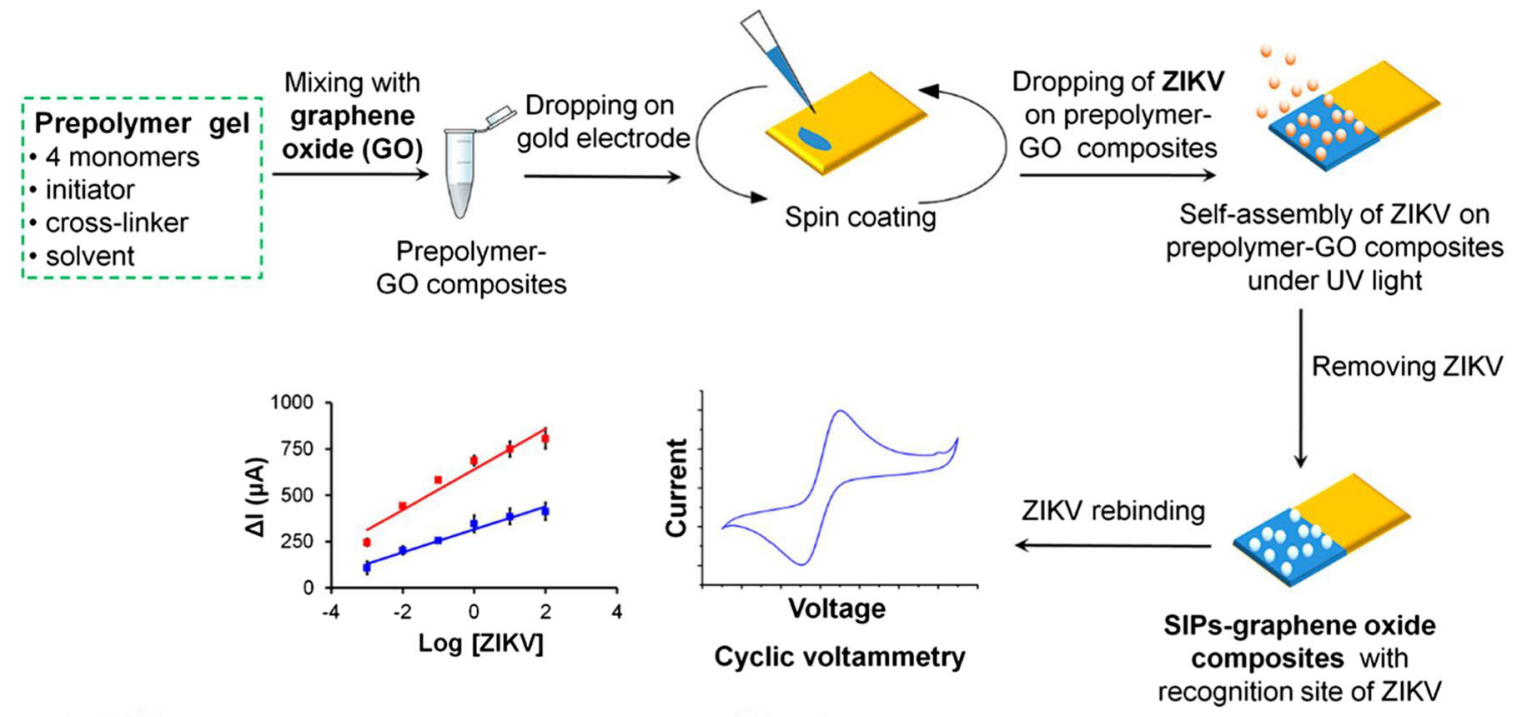

b

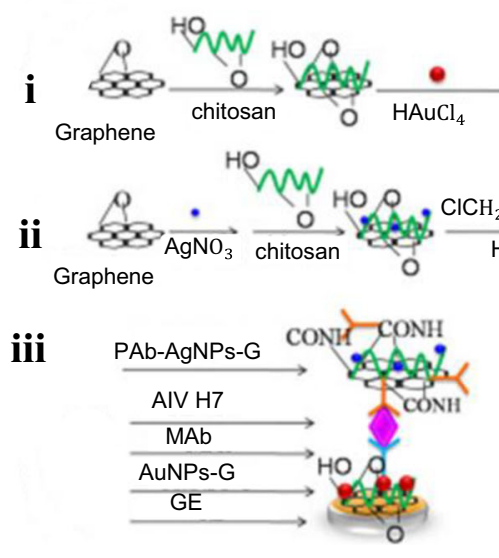

Fig. 2 a Schematic representation of SIPs-GO composites on the gold surface to detect Zika virus by creating cavities on polymer to recognize virus. Reprinted with permission from the ref. [89] Copyright 2019 American Chemical Society. b (i) AuNP-G nanocomposites fabrication, (ii) PAb-AgNP-G bioconjugates fabrication. (iii) Illustration of the

for signal amplification for an electrochemical immunosensor design. The immobilization of the antibodies (both monoclonal antibodies (MAbs) and polyclonal antibodies (PAbs)) was carried out via graphene nanocomposite layer on AuNPs and silver nanoparticles (AgNPs), respectively. The sensing platform utilized silver nanoparticle-graphene (AgNPs-G) to conduct sandwich-type immunoassay. The functionalization of the AuNPs and AgNPs, and detection mechanism were displayed in Fig. 2b. The sensor platform exhibited a dynamic working range from $1.6 \times 10^{-3}$ to $\sim 16 \mathrm{ng} / \mathrm{mL}$ with a detection limit of $1.6 \mathrm{pg} / \mathrm{mL}$ due to the high signal amplification [32]. Another graphene-based sensor platform was designed on microfluidics and electrochemical immunosensor to detect influenza virus (H1N1) in the range of 1 to $10^{4} \mathrm{pfu} / \mathrm{mL}$. The when the limit of detection (LOD) value was observed as $0.5 \mathrm{pfu} / \mathrm{mL}$. This sensing platform relied on covalently immobilized antibodies on rGO, which were placed on the
C

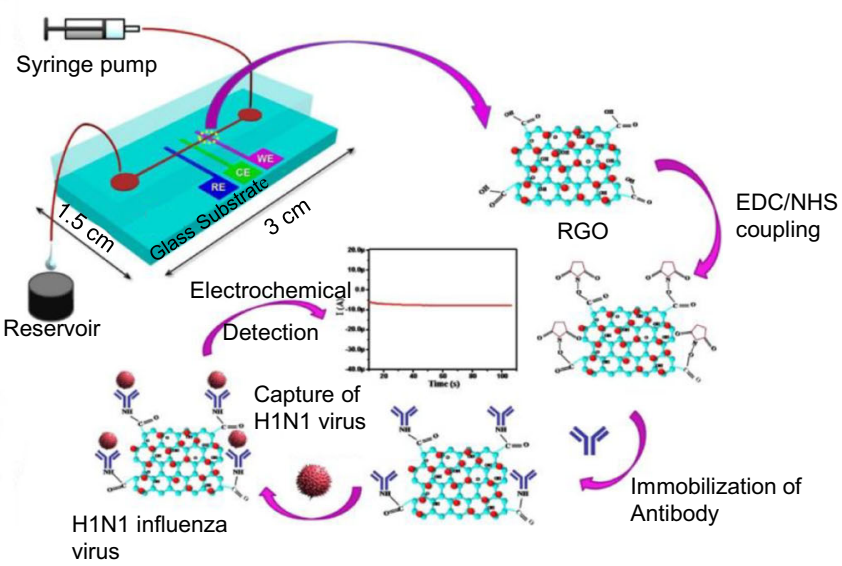

detection mechanism. Copyright permission for reuse from the ref. [32]. c Schematic representation of microfluidics-integrated electrochemical immunosensor, antibody immobilization on rGO via EDC/NHS linkers. Copyright permission for reuse from the ref. [70]

working electrode, to ensure high surface for functionalization with an antibody against target virus as summarized in Fig. 2c. As a consequence, sensitivity and selectivity were improved by eliminating many defects and electroactive sites with labelfree detection [70].

Recently, a FET-based biosensor was developed for the detection of intact SARS-CoV-2 viral particles [68]. Briefly, the FET sensor was coated with graphene sheets, functionalized with antibodies against SARS-CoV-2 spike protein. The biosensor performance was benchmarked with antigen proteins, cultured viruses, and real patient samples from nasopharyngeal swab specimens collected from COVID-19 patients. This platform achieved to detect SARS-CoV-2 spike proteins as low as $1 \mathrm{fg} / \mathrm{mL}$ in PBS solution and $100 \mathrm{fg} / \mathrm{mL}$ in clinical transport medium, as well as intact viruses down to $1.6 \times$ $10^{1} \mathrm{pfu} / \mathrm{mL}$ in culture medium and $2.42 \times 10^{2}$ copies $/ \mathrm{mL}$ in clinical samples. On a parallel track, a start-up company 
(Grapheal) introduced a rapid COVID-19 screening test based on graphene sensors, directly detecting viral particles from saliva samples [91]. Moreover, graphene field-effect transistors (Gr-FET) demonstrated molecular interactions between SARS-CoV spike S1 subunit protein antibody (CSAb) and COVID-19 spike S1 subunit protein (which contains the RBD antigens) [69]. The CSAb-modified Gr-FET was able to detect $\mathrm{S} 1$ antigens at a LOD of $0.2 \mathrm{pM}$ concentration within $2 \mathrm{~min}$. Interestingly, CSAb-decorated sensor possessed a higher sensitivity compared to its counterpart with ACE2 receptors that depicted the higher bonding affinity of CSAb to S1 $\left(K=2 \times 10^{11} \mathrm{M}^{-1}\right)$ than that of ACE2 $\left(\mathrm{K}=10^{9} \mathrm{M}^{-1}\right)$.

In addition, molecular genetic strategies have been integrated with graphene materials to detect viral infections. For instance, in order to detect Ebola genes, GO was combined with rolling circle amplification (RCA) strategy, an isothermal amplification technique of circular primers as the template to extend the DNA length that addresses the major challenges in regular PCR techniques, requiring multiple cvs during the amplification process [87]. On the course of the amplification, a double-stranded DNA was formed between fluorescein amidate (FAM)-labeled probes and RCA products. FAMlabeled detection probes were desorbed on GO surface and the fluorescence signal was recovered. On the contrary, when the sample lacked Ebola genes, RCA would not occur, and FAM-labeled detection probe would be consequently absorbed by GO surface, resulting in fluorescence quenching. The platform enabled the detection of Ebola genes down to $1.4 \mathrm{pM}$ from both aqueous solution and $1 \%$ of serum solutions.

\subsubsection{Light-sensitive materials}

Recent progressions in materials science and nanotechnology are as a conclusion of the improvement of engineered nanoparticles. Light-sensitive nanoparticles (LSNPs) have been expeditiously used for biomedical applications, and AuNPs are tremendously special among them because of their particular features, including ease-of-synthetic manipulation, unique tunable optical and distinctive electronic properties, high X-ray absorption coefficient that, allow accurate control over the particle's physicochemical properties, strong binding affinity to amines, disulfides and thiols, excellent biocompatibility and low toxicity in therapeutics, chemical and biological sensing, detection and diagnostics, drug delivery, imaging, nonlinear optics, phototherapy, photovoltaics, and catalysis fields [92-102]. Thanks to photonic band gaps (PBGs), LSNPs present or mask distinct colors. PBGs are determined by the parameters such as the crystal structure, the refractive index contrast between the individual dielectric constituents, and lattice parameters [103]. PBGs can change photonic characters of particles through temperature, mechanical or electromagnetic forces, light, and chemical applications, and photonic particles (PPs) have mainly 3 geometries that are one dimensional (1D), two dimensional (2D), and three dimensional (3D) [104-108]. PPs are initially prepared from bare opals featured polymers and then different additional materials penetrate to the opals or inverse opals in order to modulate new properties [109-116]. Moreover, PPs-coated with dielectric constant of materials, such as gold and silver or AuNPs, generate intrinsic localized surface plasmon resonance (SPR) in the visible and infrared region, which can be regulated by changing the characterization of particles, such as size, shape, aspect ratio, stability, solubility functionality, environment, and the metal film thickness [117-126] [127-129]. Photonic characteristics of composite colloids are mainly altered by engineering topology and composition [130]. Due to their plasmonic anisotropic shapes, the PPs-coated inverse opals exhibit two separate transverse and longitudinal SPR bands, thereby making them convenient for in vivo applications, yet they are rarely preferred due to their low hardiness structure $[122,131-135]$. AuNPs are mainly synthesized with three different ways: physical, chemical, and biological methods. For instance, (i) microwave irradiation, $\gamma$-irradiation, sonochemical, ultraviolet radiation, laser ablation, and thermolytic process are the physical methods [136-140]. (ii) In the chemical methods, the common agents such as citrate sodium borohydride, and alkanethiols are employed, and mostly, the Turkevich and Brust-Schfrinn procedures are applied [140-143]. (iii) Biological syntheses are taken places in biological machinery/entities plants, bacteria, fungi, algae viruses, and yeast [141, 144, 145].

From an application perspective, light-sensitive materials have been previously developed for diagnostic and therapeutic approaches for the detections of bacteria and viruses [29, 35, 146-153]. For instance, a localized SPR-stimulated immunofluorescence nanobiosensor was designed with AuNPs/ alloyed-quantum dots (QDs) for the detection of influenza virus (H1N1) [146]. The surfaces of L-cysteine-coated AuNPs were utilized to trigger fluorescence-enhancement alterations in the QDs, which were the proportional to the concentration of the viruses. The first impulse of measured QDs were at $608 \mathrm{~nm}$ and the maximum signal was observed at $634 \mathrm{~nm}$, where the plasmon emission was the highest. The platform provided the LOD of $0.03 \mathrm{pg} / \mathrm{mL}$ in ultrapure water, and this study demonstrated the versatility of the photonic materials as a nanobiosensor for detecting viruses. In another application, AuNPs and the cadmium-telluride quantum dots (CdTe-QDs) were combined to fabricate a SPR energy transfer-based biosensor for the detection of Citrus tristez a - an agent of the most detrimental disease named tristeza [147]. For this purpose, after extraction of viruses from plants, they used and combined AuNPs/CdTe-QDs for the labeling of antibodies and antigens. As a result of this study, 1:8.5 AuNPs/CdTe-QDs ratio was established for the best plasmon resonance energy transfer, and the accuracy of sensor was much more powerful 
than a common ELISA. In another study, a naked-eye detection strategy was adopted to AuNPs functionalized with thiolmodified antisense oligonucleotides (ASOs) for selective SARS-CoV-2 detection [29]. Briefly, modified nanoparticles were specific to SARS-CoV-2 nucleocapsid phosphoprotein, resulting in detectable color changes while captured by the antibodies. As an outcome, this method revealed a highselective and visual system, minimizing the need for sophisticated instrumentations. Moreover, an indirect immunochromatography method was designed as a lateral LFA utilizing colloidal AuNPs [148]. For the preparation of test lines, the SARS-CoV-2 nucleoproteins were coated on a membrane, and IgM was conjugated with AuNPs to provide the test results. The accuracy of data for this method was evaluated with RT-PCR results of COVID-19 patients, and the experiment exhibited 0.872 of co-efficiency according to the Kappa statistics ( $\kappa)$.

\subsubsection{Electrically sensitive materials}

This section elaborates the advances of electrically sensitive materials and electrochemical sensors, especially on potentiometric sensors, voltammetric sensors, and amperometric sensors. Being feasible, portable, and easy-to-construct has been dedicated considerably to provide much more attention to electrochemical sensors that are developed from expeditiously various electronic elements with new developments in nanotechnology. Briefly, potentiometric sensors measure the potential across an interface with zero-current technique [154]. The largest group among them is ion-selective electrodes that allows in determination of ion concentration with cation, anion, and neutral species in a wide range of areas provided by a reference electrode, and among them, $\mathrm{pH}$-sensitive electrodes are the most widely used [155]. The output of a potentiometric sensor depends on bulk and interfacial properties of an ionselective membrane [156]. Voltammetric sensors utilize an electroanalytic method to measure the current as a function of voltage. Several types of sensors are performed through cyclic voltammetry, squarewave voltammetry, and stripping voltammetry [62-64]. In addition, carbon-based materials, glassy carbon, graphene, carbon nanotubes, are widely employed to design the electrodes of voltammetric sensors for a myriad of reasons, including stability, low expense, simultaneously multianalyte determination, availability, and modifiability [157-159]. Amperometric sensors measure the current related to the concentration of analytes while the potential is stable [160]. In particular, non-enzymatic glucose, $\mathrm{PO}_{2}$, and hydrogen peroxide $\left(\mathrm{H}_{2} \mathrm{O}_{2}\right)$; amperometric sensors have been developed thanks to their simultaneous multiple potential use, yet still some obstacles exist in vivo implantation of these sensors [160-162]. Similar to the voltammetric sensors, novel materials, such as carbon composites, nanofibers and nanotubes, have been employed massively for amperometric sensors as well [163-165]. Electrochemical biosensors aim to measure concentration of biological analyte thanks to power of electrical signals, which are produced in an electrochemical reaction between the material and analytes. These biosensors are relatively low-cost and rapid approaches, hence they are widely used in health care, biological analysis, and food industry [166]. As an example, a sensitive and selective electrochemical-based DNA biosensor was fabricated for the detection of Ebola virus through a strategy amplifying streptavidin alkaline phosphatase enzyme [167]. For the characterization, they used differential pulse voltammetry (DPV) and the electrochemical impedance spectroscopy (EIS) that sense charge and impendence change caused by DNA immobilization on the electrode. Blocking of mobilization of DNA with $\left[\mathrm{Fe}(\mathrm{CN})_{6}\right]^{3-/ 4-}$ indicator enabled a rise in the impedance value. As a result, they achieved a remarkable success with $4.7 \mathrm{nM}$ of LOD value, and also found 0.45 regression coefficient rate, showing the selectivity of sensor.

\subsection{Detection platforms}

\subsubsection{Lateral flow assays}

Lateral flow assay (LFA) is one of the most applied diagnostic platforms in the POC and home settings, where individuals can easily operate the test through only sampling, washing, and incubating at room temperature. Compared to regular laboratory tests at the centralized settings, these tests provide results in a short period of time (5-30 min) that would help reduce the workload in the health centers remarkably, as well as low-cost would gain another advantages over the conventional test regardless providing quantitative results. LFAs are mostly utilized in hospitals, agriculture, food industry, clinical laboratories, environmental monitoring, and many other areas [168]. The working principle of the lateral flow test is facile, consisting of four overlapping parts (Fig. 3). The first part is the sample pad that contains some surface reactants to allow the sample containing the analyte to move along the pad. The liquid sample is simply applied to the sample pad, and the sample moves on the platform by capillary action. The second part is the conjugate release pad, where antibodies conjugated with AuNPs or other labels are decorated. After this step, the analyte bound to the antibodies passes over to the next compartments (membrane), where mainly two or more lines containing immobilized antibody or antigen to capture analyte molecules. In a basic design, there are test and control lines. Confirming the control line provides results, the color change in the test line indicates the capture of analytes. The latter section, i.e., absorbent pad, is the engine of the LFA and also prevents the backflow of excess liquid [168].

Considering logistic and applicability drawbacks in the conventional assays, LFAs hold potential to expand the POC assays to larger geographies, especially to low-income countries. Therefore, several companies and research groups 


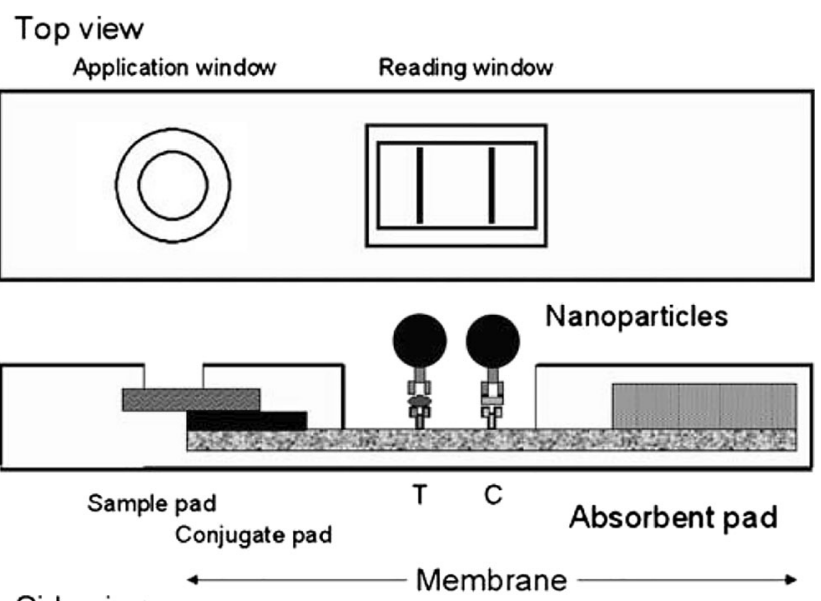

Side view

Fig. 3 Lateral flow assay format. Copyright permission for reuse from the ref. [169]

focus to produce LFA-based serological tests, for instance, an LFA test produced by the NG Biotechnology Laboratory (Guipry-Messac, France) detects both IgG and IgM antibodies against the nucleoprotein of SARS-CoV-2 viruses [170]. While benchmarking the assay performance, a cohort with three major groups was tested: (1) individuals with PCR positive, (2) people, who showed symptoms but PCR negative, and (3) persons with PCR negative (control). According to the test results, the sensitivity of the LFA tests was $31.3 \%$ on days < 7 of symptoms, $69.0 \%$ on days $8-14$, and $100 \%$ on days $>14$. Therefore, this LFA became a complementary option for the RT-qPCR test for easy expansion of screening. As an example of the actions taken, the Infectious Diseases Association of America decided that people with PCR negative but show the symptoms could be diagnosed by serological tests [171]. In some reports, it has also been observed that the RT-PCR test is negative in patients with SARS-CoV-2 virus [172], implying that some of the reasons might be sampling errors, problems in reagents, as well as uneven distribution of viruses in respiratory tract [173]. In such false-negative situations, the condition of lungs is controlled via a computerized tomography for further diagnosis [172]. For this reason, many different companies produced LFA platforms in order to have faster and more accurate results. Similarly, the LFA platform developed by BioMedomics company- detects both antibodies within $10 \mathrm{~min}$, and it is one of the most well-known examples. In addition, $\mathrm{IgG}$ antibodies can circulate in the body after the patient heals and its concentration increases to a certain level. Thanks to the LFA tests, it is also possible to detect past infections through such measurement opportunites [174]. In summary, LFAs have potential to evaluate the prevalence of pandemics in the community and enable people, who are still at risk to be identified [175].

Again, elaborating on the studies of SARS-CoV-2, antigen-based diagnostic tests could be more sensitive and reliable than serological tests, detecting viral antigens directly which are independent of the level of an individual's immune response. In view of this situation, in another study, a halfstrip of LFA targeting the nucleocapsid antigen was produced to detect the presence of the SARS-CoV-2 virus [176]. The nucleocapsid protein is one of the main proteins of the coronavirus. Half-lane LFA platform only has a nitrocellulose membrane and wick pad [176]. As another example, a group of researchers developed an LFA platform based on lanthanide-doped polystyrene (LNP) nanoparticles to detect the IgG antibody of the SARS-CoV-2 virus [177]. The LNP used here acted as a fluorescent reporter and proteins of SARS-CoV-2 were fixed with LNPs on the conjugate pad. According to this approach, if IgG antibodies against SARSCoV-2 exist, it will be captured by the proteins with LNP here. This system also addressed the challenges in other fluorescence-based LFA tests, which are interfered with poor stability of dyes and photobleaching.

In addition, the utility of LFAs in the POC settings was comprehensively evaluated with four different tests in various periods of the disease [178]. In addition, in the same study, it was investigated whether there was a difference in disease severity and antibody response in patients with COVID-19. One of the results obtained according to the study was that the usefulness of POC tests was related to the period of the disease. Three weeks after the symptoms began, the sensitivity of the tests was $100 \%$. Another result obtained was no difference between LFA-based POC tests produced by different manufacturers for COVID-19 diagnosis. The last finding was that pneumonia patients developed more rapid immune response compared to patients without pneumonia [178]. Through molecular biology integration, a CRISPR-based DETECTR LFA was designed to diagnose COVID-19 within <30 min [179]. This method was capable of isothermal amplification and reverse transcription through a loop-mediated amplification, followed by the Cas 12 detection of previously known coronavirus sequences. Finally, the presence of the virus was detected by the cleavage of the reporter molecule, and positive results were confirmed by the detection of both the envelope (E) and nucleocapsid $(\mathrm{N})$ proteins of the coronavirus on the LFA.

Despite all these advantages, there are some bottlenecks in LFA strategies: (i) antibodies could cross react, leading to false positive results with other types of coronaviruses because some proteins of coronaviruses are conserved between different species [174]. (ii) In some studies, it has been mentioned that the sensitivity of LFA tests is very low compared to the RT-PCR test. The studies conducted by Li [180] and his team have shown that the tests in which $\operatorname{IgG}$ and IgM antibodies are combined and give more sensitive and specific results than individual antibodies.

\subsubsection{Lab-on-a-chip devices}

Especially in countries with limited resources, rapid, easy-touse, inexpensive diagnoses are sought in accordance with the 
effective management of infectious diseases and POC testing. Solutions like LFAs and paper-based devices provide these features, but have difficulties such as insufficient sensitivity and selectivity. The development of technology and the inclusion of nanotechnology and microfluidics in bio-detection platforms hold great promise to advance diagnostic platforms in terms of sensitivity, specificity, and accuracy $[129,181]$. Recently, laboratory technologies built on an advanced chip that can perform a wide range of analysis by performing complex tasks with integrated systems, as well as a single task have attracted attention. Each lab-on-a-chip (LOC) platform characteristically holds groups of microfluidic elements capable of particular operations, such as reagent storage, liquid transfer, liquid mixing, target detection, and liquid collection. Looking at these systems, it is noteworthy that with their interconnected fluid microchannel networks, valves, mixers, pumps, and detectors, they can perform many laborious and highly reactive and time-consuming benchtop protocols without human intervention [182]. Microfluidic platforms have also been integrated with a variety of analytical methods, such as electrochemical analysis $[183,184]$, fluorescence analysis $[185,186]$, mass spectrometry [187], and chemiluminescence $[188,189]$. Combining smart materials with LOC devices increases the function and efficacy of various components of these platforms. [10].

In the aspect of COVID-19 diagnosis, a microfluidic platform containing a fluorescence detection analyzer (Fig. 4a), SARS-CoV-2 diagnostic microchips (Fig. 4b), and immunological tests (Fig. 4c) was developed to detect three different biomarkers (IgG, IgM, and virus antigen) [34]. This microchip included fluorescence detection, centrifugation, and result display features on the same platform. Matrix nanospotting strategy was employed while preparing the immunoassay chip for biomarkers, and thereby, each marker was patterned on the surface of the bottom substrate layer. The microchip was designed and manufactured by combining top and bottom plates made of polycarbonate, sandwiching the middle layer that contains a channel for the sample analysis. In this design, three samples were able to be analyzed simultaneously using a fluorescence detector. In another study, a LAMP assay-based diagnostic test targeting the $\mathrm{N}$ gene was designed and optimized according to the reported sequences [190]. The platform was designed on a disposable cartridge containing microfluidic channels. The RT-LAMP assay was performed on a large array of more than 4000 sensors called ion-sensitive fieldeffect transistors that monitor nucleic acid amplification through the release of protons in the reaction associated with nucleotide incorporation during LAMP. Each cartridge had a 3D printed microfluidic manifold in a transparent biocompatible resin. The sealing between the manifold and the chip surface was achieved with laser cut double rod adhesive gaskets with an $\mathrm{Ag} / \mathrm{AgCl}$ reference electrode passing through each reaction well between the chip surface and the band seal.
The developed LAMP test was compared with RT-qLAMP using clinical samples, showing sensitivity $\sim 90 \%$ and specificity of $100 \%$.

Considering the integration of LOC systems with sensors, a bifunctional plasmonic biosensor harmonizing both plasmonic photothermal (PPT) effect and localized surface plasmon resonance (LSPR) sensing was presented as an alternative platform for COVID-19 diagnosis [191]. Sensitive detection of sequences for SARS-CoV-2 was achieved by nucleic acid hybridization of 2D gold nano islands (AuNIs), functionalized with complementary DNA sequences. Better recognition of SARS-CoV-2 performance was achieved on the same AuNIs plasmonic chip when thermoplasmonic heat was illuminated at plasmonic resonance frequencies. This new sensor denoted a high sensitivity to SARS-CoV-2 with an LOD of $0.22 \mathrm{pM}$ concentration.

An automatic centrifugal microfluidic system consisting of a microfluidic disk and a specialized device was developed to detect RNAs of SARS-CoV-2 [192]. In the designed system, there was a centrifugal microfluidic disc consisting of 21 identical reaction units. The disc included three layers: (i) the first layer was embedded with poly (methyl methacrylate) reaction units, (ii) the second layer was designed to reservoir sample and reagent injection holes, and (iii) the third layer was for sealing. Each unit contained three chambers for loading reagents, samples, nucleic acid release, and RT-LAMP reaction. After the swab samples were injected into the microfluidic disk, all processing steps including sample processing, RTLAMP, and fluorescence signal detection could be performed in the automated system. In sum, microfluidic systems are successful alternatives that would increase the diagnostic efficiency of infectious diseases through presenting multiple alternatives to the common detection strategies and umpteen integration capability with distinct sensor platforms that accelerate rapid detection of viral nucleic acids, antigens, or antibodies without the need for experts and sophisticated equipment.

\subsubsection{Wearable intelligent materials}

Wearable intelligent materials have gained great interest in the field of health care over the last decade, implementing facile and easy-adaptable platforms without any disruptions to our daily lives. Wearable smart materials can be attached directly to any part of the body, and also they can be accessories, such as watches, glasses, necklaces, and bracelets to monitor continuous parameters released from body. As an example, smart t-shirts and shoes are equipped with sensors to collect data and health information since individuals can easily carry them throughout the day [193]. The information collected from these devices include body temperature, heart rate, and respiratory rate. For example, when a person having a wearable smart material has a sudden heart attack, the device transmits 


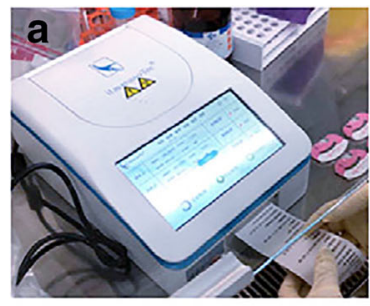

b

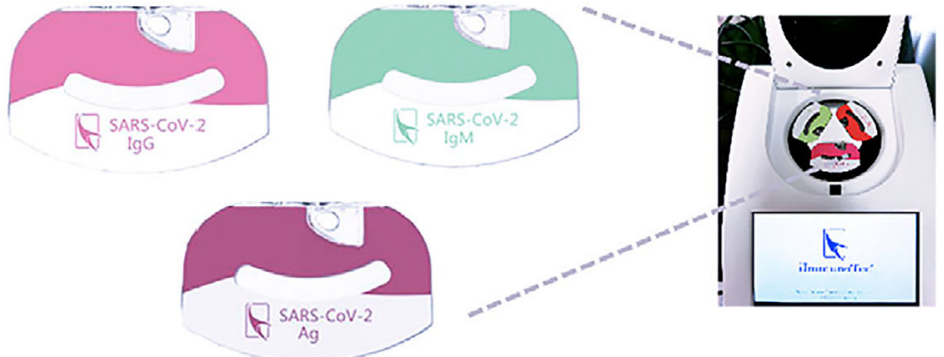

C

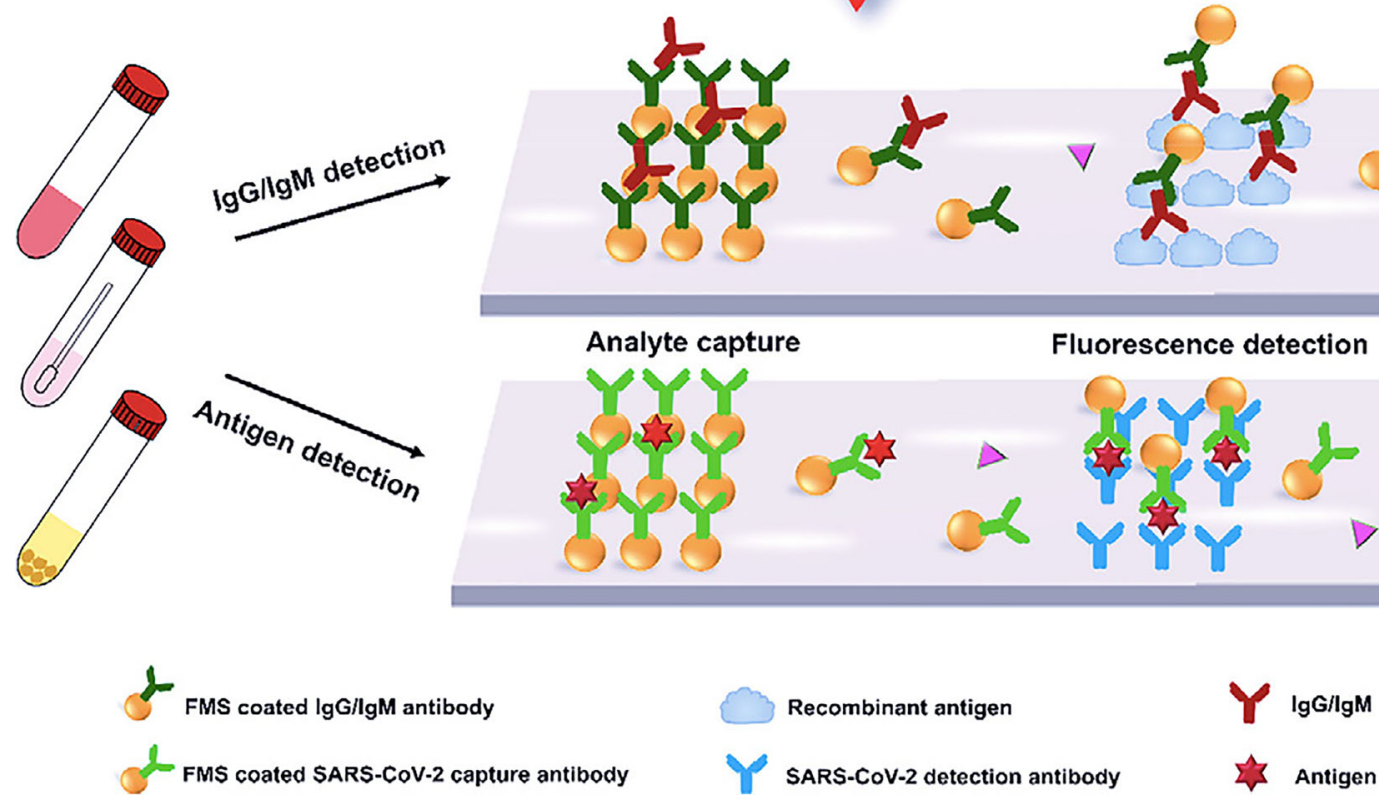

Fig. 4 a A portable fluorescence detection equipment. b Ready to use immunoassay chip. $\mathbf{c}$ Schematic illustration of the microfluidic fluorescence immunoassay biomarkers of SARS-CoV-2. Copyright permission for reuse from the ref. [34]

this information to the doctor to take necessary interventions [194]. Likewise, many virus-borne diseases and COVID-19 have certain physiological symptoms. The most common ones could be listed as fever, cough, loss of appetite/smell and respiration problems. Today, many smart watches display heart rate, sleep quality, activity time, and some other physical information. Based on today's sensors and further implementation of smart material-based sensors to the wearables, crucial symptoms of COVID-19 could be detected even before any diagnostics tests are applied, accelerating early diagnosis, and ultimately, people would be able to isolate themselves, potentially minimizing the spread of the disease, and initiating the most accurate clinical management on time before the disease is manifested [195].

For instance, a study was conducted on observing people, who were diagnosed with COVID-19 with wearable smart material and were in the quarantine process [196]. In this study, IoT-based wearable quarantine band (IoT-QBand) was used and the people, who need to be in isolation were followed up. Hence, those who violate these rules even though they need to be quarantined could be detected and necessary measures were taken accordingly. A group of researchers at Northwestern University achieved to record the severity, frequency, and duration of people's cough using a sensor that they designed to be placed in the suprasternal notch [197], making it possible for them to diagnose COVID-19. On a parallel track, the researchers from University College Cork and their colleagues from a software company developed a wearable device called COVID-19 Remote Early Warning System (CREW) that detects another most common symptom in COVID-19, i.e., high temperature [198]. This device consists of a wearable thermometer sensor that measures body temperature, a mobile phone-based platform for the operation, and a cloud system for the data collection. This device, which was first tested on employees at Cork University Hospital, reported employees, whose body temperature exceeds the critical value of the master data system, and in this case, they enabled the employee to take the necessary precautions and isolate themselves. Another study is being conducted

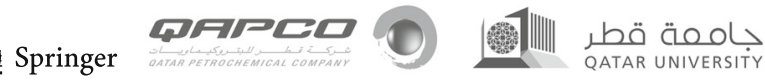


by Oura Health with some researchers at the University of West Virginia [195, 199], and with a wearable smart ring, they focused on the detection of SARS-CoV-2 virus in health care workers and other people, who have not yet started to show any symptoms. The onset of individuals' symptoms such as fever, cough, and shortness of breath were determined with the help of artificial intelligence algorithms, providing results with $90 \%$ accuracy approximately 3 days before the symptoms appear.

Wearable smart materials integrated with sensors collect enormous amount of data through human physiology every day. These devices allow many elderly people to follow their physiological conditions without the need for special training and without difficulty. In another study, vital signs were measured using some development boards, phones, and headsets, together with the mask, which is one of the most important measures taken against COVID-19 [200]. Phone, headset, and microphone were used in the study. Thanks to the microphone in the mask, information about respiratory rate and cough were recorded by any voice recording program on the phone. This audio file was then imported into the computational application for data acquisition and analysis for cough intensity and the duration of breathing. The role of the headset also ensured that the person using this device received immediate feedback. If a problem was detected, this situation would be reported to the individual [200]. Thus, if a person had a problem with cough and breathing, they could provide a possible early diagnosis. Overall, we here provided a representative table to compare some of the aforementioned platforms (Table 1).

\section{Conclusions}

In this review, we have elaborated how smart materials could be integrated into biosensor systems and how they could be useful in the diagnosis of COVID 19. On the course of this pandemic, the entire world has tried to find a proper solution in the realms of biosensing and materials science with the examples, not limited to, platforms employing light-active/ sensitive and electrical sensitive materials, microfluidic platforms, LFAs, and wearable materials. Biosensors have fantastic features, such as being a rapid alternative to lengthy procedures in the current practice, being single-use to avoid any potential contaminations or infections, and minimizing the need for experts and centralized laboratories equipped with high-cost tolls. Smart materials-integrated systems pave the way to provide multifaceted capabilities to current biosensors, including enhancements in sensitivity, specificity, and accuracy, as well as creating new sensor designs, such as hybrid modalities. With this mutual integration, state-of-the-art biosensors would enable detect minute concentrations of more accuracy like antibodies, viral antigens, nucleic acids, and

Table 1 Comparison of different smart material-integrated sensor systems

\begin{tabular}{|c|c|c|c|c|c|}
\hline Sensor type & Target & Recognition element & Ref. & Advantages & Disadvantages \\
\hline $\begin{array}{c}\text { Graphene-polymer } \\
\text { systems }\end{array}$ & $\begin{array}{l}\text { SARS-CoV-2 spike } \\
\text { protein }\end{array}$ & $\begin{array}{l}\text { Graphene sheets functionalized with } \\
\text { spike protein of virus }\end{array}$ & {$[68]$} & $\begin{array}{l}\text { - Low manufacturing cost } \\
\text { - High specific surface area } \\
\text { - Good biocompatibility }\end{array}$ & $\begin{array}{l}\text { - Paucity of band gap } \\
\text { - Hard to obtain high quality }\end{array}$ \\
\hline $\begin{array}{l}\text { Light-sensitive } \\
\text { material-based } \\
\text { systems }\end{array}$ & $\begin{array}{l}\text { SARS-CoV-2 } \\
\text { nucleoprotein }\end{array}$ & AuNPs conjugated IgM & [148] & $\begin{array}{l}\text { - Strong absorption ability } \\
\text { of light } \\
\text { - Facilitates the } \\
\text { colorimetric } \\
\text { determination }\end{array}$ & $\begin{array}{l}\text { - Hard to control the size of } \\
\text { AuNPs }\end{array}$ \\
\hline $\begin{array}{l}\text { Electrically sensitive } \\
\text { material-based } \\
\text { systems }\end{array}$ & Ebola virus DNA & $\begin{array}{l}\text { Streptavidin alkaline phosphatase } \\
\text { enzyme-labeled electrode }\end{array}$ & {$[167]$} & $\begin{array}{l}\text { - Easy-to-prepare } \\
\text { - High } \\
\text { chemical/mechanical } \\
\text { stability } \\
\text { - Miniaturization }\end{array}$ & $\begin{array}{l}\text { - Sensitive to } \mathrm{pH} \text { or ionic } \\
\text { components in sample } \\
\text { solution }\end{array}$ \\
\hline Lateral flow assays & $\begin{array}{l}\text { SARS-CoV-2 } \\
\text { nucleoprotein }\end{array}$ & Antibodies against nucleoproteins & {$[170]$} & $\begin{array}{l}\text { - Short turnaround time } \\
\text { - Low-cost } \\
\text { - Reduced workload }\end{array}$ & $\begin{array}{l}\text { - Mostly qualitative or } \\
\text { semiquantitative results }\end{array}$ \\
\hline $\begin{array}{l}\text { Lab-on-a-chip } \\
\text { devices }\end{array}$ & $\begin{array}{l}\text { SARS-CoV-2 (IgG, } \\
\text { IgM and viral } \\
\text { antigen) }\end{array}$ & $\begin{array}{l}\text { Specific patterns for } \operatorname{IgG}, \operatorname{IgM} \text { and } \\
\text { virus antigen using nanospotting } \\
\text { strategy }\end{array}$ & {$[34]$} & $\begin{array}{l}\text { - Miniaturization } \\
\text { - Small sample volume } \\
\text { - Portability } \\
\text { - Rapid detection time }\end{array}$ & $\begin{array}{l}\text { - Expensive fabrication } \\
\text { methods }\end{array}$ \\
\hline $\begin{array}{c}\text { Wearable intelligent } \\
\text { materials }\end{array}$ & Temperature & High temperature tracking & [198] & $\begin{array}{l}\text { - Simultaneous monitoring } \\
\text { - Easy-adaptable without } \\
\text { any disruptions to daily } \\
\text { lives }\end{array}$ & $\begin{array}{l}\text { - Requirement of user } \\
\text { friendly design }\end{array}$ \\
\hline
\end{tabular}


intact viruses. Through wearable sensing strategies, these smart sensors would be implemented to our daily lives easily, enabling self-monitoring and remote-control of diseases, thereby democratizing the POC-based diagnostic platforms that are majorly not reachable in low-income countries, and minimizing disparities in this manner across the globe.

Funding F.I. received the support from TÜBİTAK 2232 International Fellowship for Outstanding Researchers. This publication has been produced benefiting from the 2232 International Fellowship for Outstanding Researchers Program of TÜBİTAK (Project No: 118C254). However, the entire responsibility of the publication/paper belongs to the owner of the publication/paper. The financial support received from TÜBITTAK does not mean that the content of the publication is approved in a scientific sense by TÜBITTAK.

\section{Compliance with ethical standards}

Conflict of interest The authors declare that they have no conflict of interest.

\section{References}

1. L. Bennet, The common cold. J. Gen. Intern. Med. 11, 229-236 (1996)

2. P. Palese, Influenza: old and new threats. Nat. Med. 10, S82-S87 (2004)

3. D.A. Henderson, Clinical and epidemiologic characteristics of smallpox. Emerg. Infect. Dis. 5, 537-539 (1999)

4. M.Z. Yousaf, M. Qasim, S. Zia, M.u.R. Khan, U.A. Ashfaq, S. Khan, Rabies molecular virology, diagnosis, prevention and treatment. Virol. J. (2012). https://doi.org/10.1186/1743-422X-9-50

5. J.J. Farrar, P. Piot, The ebola emergency-immediate action, ongoing strategy. N. Engl. J. Med. 371, 1545-1546 (2014)

6. F. Barré-Sinoussi, J.C. Chermann, F. Rey, et al., Isolation of a Tlymphotropic retrovirus from a patient at risk for acquired immune deficiency syndrome (AIDS). Rev. Investig. Clin. 56, 126-129 (2004)

7. R.H. Purcell, Hepatitis viruses: changing patterns of human disease. Proc. Natl. Acad. Sci. U. S. A. 91, 2401-2406 (1994)

8. R. Higginson, K. Davies, The threat of an avian influenza pandemic. Br. J. Nurs. 14, 632 (2005)

9. N. Petrosillo, G. Viceconte, O. Ergonul, G. Ippolito, E. Petersen, COVID-19, SARS and MERS: are they closely related? Clin. Microbiol. Infect. 26, 729-734 (2020)

10. N. Bhalla, Y. Pan, Z. Yang, A.F. Payam, Opportunities and challenges for biosensors and nanoscale analytical tools for pandemics: COVID-19. ACS Nano 14, 7783-7807 (2020)

11. E. Vermisoglou, D. Panáček, K. Jayaramulu, M. Pykal, I. Frébort, M. Kolář, M. Hajdúch, R. Zbořil, M. Otyepka, Human virus detection with graphene-based materials. Biosens. Bioelectron. 166, 112436 (2020). https://doi.org/10.1016/j.bios.2020.112436

12. E. Alphandéry, The potential of various nanotechnologies for coronavirus diagnosis/treatment highlighted through a literature analysis. Bioconjug. Chem. (2020). https://doi.org/10.1021/acs. bioconjchem.0c00287

13. S.R. Ahmed, J. Kim, T. Suzuki, J. Lee, E.Y. Park, Enhanced catalytic activity of gold nanoparticle-carbon nanotube hybrids for influenza virus detection. Biosens. Bioelectron. 85, 503-508 (2016)
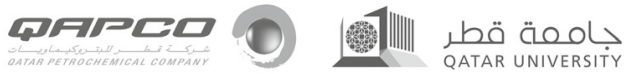

14. M.-Y. Xu, S.-Q. Liu, C.-L. Deng, Q.-Y. Zhang, B. Zhang, Detection of Zika virus by SYBR green one-step real-time RTPCR. J. Virol. Methods 236, 93-97 (2016)

15. Z.P. Morehouse, C.M. Proctor, G.L. Ryan, R.J. Nash, A novel two-step, direct-to-PCR method for virus detection off swabs using human coronavirus 229E. Virol. J. 17, 1-6 (2020)

16. Y. Saylan, Ö. Erdem, S. Ünal, A. Denizli, An alternative medical diagnosis method: biosensors for virus detection. Biosensors 9, 65 (2019)

17. G.K. Nasrallah, S.R. Dargham, A.S. Sahara, M.S. Elsidiq, L.J. Abu-Raddad, Performance of four diagnostic assays for detecting herpes simplex virus type 2 antibodies in the Middle East and North Africa. J. Clin. Virol. 111, 33-38 (2019)

18. M. Zafrullah, X. Zhang, C. Tran, M. Nguyen, S. Kamili, M.A. Purdy, S.L. Stramer, Disparities in detection of antibodies against hepatitis E virus in US blood donor samples using commercial assays. Transfusion 58, 1254-1263 (2018)

19. D.M. Cutler, L.H. Summers, The COVID-19 pandemic and the $\$ 16$ trillion virus. JAMA. (2020). https://doi.org/10.1001/jama. 2020.19759

20. P. Innocenzi, L. Stagi, Carbon-based antiviral nanomaterials: graphene, C-dots, and fullerenes. a perspective. Chem Sci 10, 6606-6622 (2020)

21. S. Mahendiratta, G. Batra, P. Sarma, H. Kumar, S. Bansal, S. Kumar, A. Prakash, R. Sehgal, B. Medhi, Molecular diagnosis of COVID-19 in different biologic matrix, their diagnostic validity and clinical relevance: a systematic review. Life Sci. 258, 118207 (2020)

22. I. Astuti, Ysrafil, Severe acute respiratory syndrome coronavirus 2 (SARS-CoV-2): an overview of viral structure and host response. Diabetes Metab. Syndr. Clin. Res. Rev. 14, 407-412 (2020)

23. A.M. Wen, N.F. Steinmetz, Design of virus-based nanomaterials for medicine, biotechnology, and energy. Chem. Soc. Rev. 45, 4074-4126 (2016)

24. G.K. Knopf, A.S. Bassi, Smart biosensor technology. Second edition (CRC press) (2018)

25. Y. Parepalli, T.V. Aradhyula, M. Chavali, Smart materials in nanoscience and nanotechnology - an overview. Int J Nanosci Nanotechnol 3, 9-14 (2014)

26. R. Verma, R.R. Adhikary, R. Banerjee, Smart material platforms for miniaturized devices: implications in disease models and diagnostics. Lab Chip 16, 1978-1992 (2016)

27. N. Chauhan, T. Maekawa, D.N.S. Kumar, Graphene based biosensors - accelerating medical diagnostics to new-dimensions. J. Mater. Res. 32, 2860-2882 (2017)

28. R. Hajian, S. Balderston, T. Tran, et al., Detection of unamplified target genes via CRISPR-Cas9 immobilized on a graphene fieldeffect transistor. Nat Biomed Eng 3, 427-437 (2019)

29. P. Moitra, M. Alafeef, M. Alafeef, M. Alafeef, K. Dighe, M.B. Frieman, D. Pan, D. Pan, D. Pan, Selective naked-eye detection of SARS-CoV-2 mediated by $\mathrm{N}$ gene targeted antisense oligonucleotide capped plasmonic nanoparticles. ACS Nano 14, 7617-7627 (2020)

30. T.T. Le, B. Adamiak, D.J. Benton, C.J. Johnson, S. Sharma, R. Fenton, J.W. McCauley, M. Iqbal, A.E.G. Cass, Aptamer-based biosensors for the rapid visual detection of flu viruses. Chem. Commun. 50, 15533-15536 (2014)

31. L.A. Layqah, S. Eissa, An electrochemical immunosensor for the corona virus associated with the Middle East respiratory syndrome using an array of gold nanoparticle-modified carbon electrodes. Microchim. Acta (2019). https://doi.org/10.1007/s00604-0193345-5

32. J. Huang, Z. Xie, Z. Xie, S. Luo, L. Xie, L. Huang, Q. Fan, Y. Zhang, S. Wang, T. Zeng, Silver nanoparticles coated graphene electrochemical sensor for the ultrasensitive analysis of avian influenza virus H7. Anal. Chim. Acta 913, 121-127 (2016) 
33. H. Shafiee, E.A. Lidstone, M. Jahangir, F. Inci, E. Hanhauser, T.J. Henrich, D.R. Kuritzkes, B.T. Cunningham, U. Demirci, Nanostructured optical photonic crystal biosensor for HIV viral load measurement. Sci. Rep. 4, 1-7 (2014)

34. Q. Lin, D. Wen, J. Wu, L. Liu, W. Wu, X. Fang, J. Kong, Microfluidic immunoassays for sensitive and simultaneous detection of $\mathrm{IgG} / \mathrm{IgM} /$ antigen of SARS-CoV-2 within $15 \mathrm{~min}$. Anal. Chem. 92, 9454-9458 (2020)

35. R. Samson, G.R. Navale, M.S. Dharne, Biosensors: frontiers in rapid detection of COVID-19. 3. Biotech 10, 1-9 (2020)

36. J. Yee, L. Unger, F. Zadravecz, P. Cariello, A. Seibert, M.A. Johnson, M.J. Fuller, Novel coronavirus 2019 (COVID-19): emergence and implications for emergency care. J Am Coll Emerg Physicians Open 1, 63-69 (2020)

37. Z.Y. Zu, M. Di Jiang, P.P. Xu, W. Chen, Q.Q. Ni, G.M. Lu, L.J. Zhang, Coronavirus disease 2019 (COVID-19): a perspective from China. Radiology 296, E15-E25 (2020)

38. H.A. Rothan, S.N. Byrareddy, The epidemiology and pathogenesis of coronavirus disease (COVID-19) outbreak. J. Autoimmun. 109, 102433 (2020)

39. T.P. Velavan, C.G. Meyer, The COVID-19 epidemic. Trop Med Int Heal 25, 278-280 (2020)

40. M. Cascella, M. Rajnik, A. Cuomo, S.C. Dulebohn, R. Di Napoli, Features, evaluation and treatment coronavirus (COVID-19). Statpearls (2020)

41. World Health Organization, WHO Coronavirus Disease (COVID19) Dashboard. https://covid19.who.int/?gclid=CjwKCAiAlNfBRB_EiwA2osbxTySf8rjMYJNA gZYFKDQpxaG52T69zQGGUGhu8bKccDt1TGNC-n4hoCcYAQAvD_BwE. Accessed 13 Oct 2020 (2020)

42. J. Zheng, SARS-CoV-2: an emerging coronavirus that causes a global threat. Int. J. Biol. Sci. 16, 1678 (2020)

43. P. Zhai, Y. Ding, X. Wu, J. Long, Y. Zhong, Y. Li, The epidemiology, diagnosis and treatment of COVID-19. Int. J. Antimicrob. Agents 55, 105955 (2020)

44. S.M. Moghadas, M.C. Fitzpatrick, P. Sah, A. Pandey, A. Shoukat, B.H. Singer, A.P. Galvani, The implications of silent transmission for the control of COVID-19 outbreaks. Proc. Natl. Acad. Sci. 117, 17513-17515 (2020)

45. K.A. Walsh, K. Jordan, B. Clyne, et al., SARS-CoV-2 detection, viral load and infectivity over the course of an infection. J. Inf. Secur. 81, 357-371 (2020)

46. Y. Fang, Y. Nie, M. Penny, Transmission dynamics of the COVID-19 outbreak and effectiveness of government interventions: a data-driven analysis. J. Med. Virol. 92, 645-659 (2020)

47. A. Koirala, Y.J. Joo, A. Khatami, C. Chiu, P.N. Britton, Vaccines for COVID-19: the current state of play. Paediatr. Respir. Rev. 35, 43-49 (2020)

48. J.M. Sanders, M.L. Monogue, T.Z. Jodlowski, J.B. Cutrell, Pharmacologic treatments for coronavirus disease 2019 (COVID-19): a review. Jama 323, 1824-1836 (2020)

49. World Health Organization, DRAFT landscape of COVID-19 candidate vaccines. https://www.who.int/publications $/ \mathrm{m} /$ item/ draft-landscape-of-covid-19-candidate-vaccines. Accessed 13 Oct 2020 (2020)

50. Y.-W. Tang, J.E. Schmitz, D.H. Persing, C.W. Stratton, The laboratory diagnosis of COVID-19 infection: current issues and challenges. J Clin Microbiol 58(6), e00512-e00520 (2020)

51. R. Liu, H. Han, F. Liu, Z. Lv, K. Wu, Y. Liu, Y. Feng, C. Zhu, Positive rate of RT-PCR detection of SARS-CoV-2 infection in 4880 cases from one hospital in Wuhan, China, from Jan to Feb 2020. Clin. Chim. Acta 505, 172-175 (2020)

52. V.M. Corman, O. Landt, M. Kaiser, R. Molenkamp, A. Meijer, D.K.W. Chu, T. Bleicker, S. Brünink, J. Schneider, M.L. Schmidt, Detection of 2019 novel coronavirus (2019-nCoV) by real-time RT-PCR. Eurosurveillance 25, 2000045 (2020)
53. J.J. Waggoner, V. Stittleburg, R. Pond, Y. Saklawi, M.K. Sahoo, A. Babiker, L. Hussaini, C.S. Kraft, B.A. Pinsky, E.J. Anderson, Triplex real-time RT-PCR for severe acute respiratory syndrome coronavirus 2. Emerg. Infect. Dis. 26, 1633 (2020)

54. B. Dharavath, N. Yadav, S. Desai, R. Sunder, R. Mishra, M. Ketkar, P. Bhanshe, A. Gupta, A.K. Redhu, N. Patkar, A one-step, one-tube real-time RT-PCR based assay with an automated analysis for detection of SARS-CoV-2. Heliyon 6, e04405 (2020)

55. A. Tahamtan, A. Ardebili, Real-time RT-PCR in COVID-19 detection: Issues affecting the results. Expert Rev Mol Diagn. 20(5), 453-454 (2020)

56. D.-G. Ahn, H.-J. Shin, M.-H. Kim, S. Lee, H.-S. Kim, J. Myoung, B.-T. Kim, S.-J. Kim, Current status of epidemiology, diagnosis, therapeutics, and vaccines for novel coronavirus disease 2019 (COVID-19). J Microbiol Biotechnol 28;30(3), 313-324 (2020)

57. M.L. Bastos, G. Tavaziva, S.K. Abidi, J.R. Campbell, L.-P. Haraoui, J.C. Johnston, Z. Lan, S. Law, E. MacLean, A. Trajman, Diagnostic accuracy of serological tests for covid-19: systematic review and meta-analysis. BMJ 370, m2516 (2020)

58. V. Roy, S. Fischinger, C. Atyeo, M. Slein, C. Loos, A. Balazs, C. Luedemann, M.G. Astudillo, D. Yang, D. Wesemann, SARSCoV-2-specific ELISA development. J. Immunol. Methods 484485, $112832(2020)$

59. T. Wen, C. Huang, F.-J. Shi, X.-Y. Zeng, T. Lu, S.-N. Ding, Y.-J. Jiao, Development of a lateral flow immunoassay strip for rapid detection of IgG antibody against SARS-CoV-2 virus. Analyst 145, 5345-5352 (2020)

60. C.W. Tan, W.N. Chia, X. Qin, P. Liu, MI.-C. Chen, C. Tiu, Z. Hu, VC.-W. Chen, B.E. Young, W.R. Sia, A SARS-CoV-2 surrogate virus neutralization test based on antibody-mediated blockage of ACE2-spike protein-protein interaction. Nat Biotechnol 38, 1073-1078 (2020)

61. F. Krammer, V. Simon, Serology assays to manage COVID-19. Science (80- ) 368, 1060-1061 (2020)

62. A.K. Winter, S.T. Hegde, The important role of serology for COVID-19 control. Lancet Infect. Dis. 20, 758-759 (2020)

63. X. Yu, H. Cheng, M. Zhang, Y. Zhao, L. Qu, G. Shi, Graphenebased smart materials. Nat Rev Mater 2, 1-14 (2017)

64. B.M. Holzapfel, J.C. Reichert, J.T. Schantz, U. Gbureck, L. Rackwitz, U. Nöth, F. Jakob, M. Rudert, J. Groll, D.W. Hutmacher, How smart do biomaterials need to be? A translational science and clinical point of view. Adv. Drug Deliv. Rev. 65, 581-603 (2013)

65. Z.-Y. Cheng, Applications of smart materials in the development of high performance biosensors. Mater. Res. 888, 1-11 (2006)

66. R. Sandulescu, M. Tertis, C. Cristea, E. Bodoki, New materials for the construction of electrochemical biosensors. Biosensors - Micro and Nanoscale Applications (2015)

67. D. Wasik, A. Mulchandani, M.V. Yates, Biosensors and bioelectronics A heparin-functionalized carbon nanotube-based affinity biosensor for dengue virus. Biosens. Bioelectron. 91, 811-816 (2017)

68. G. Seo, G. Lee, M.J. Kim, et al., Rapid detection of COVID-19 causative virus (SARS-CoV-2) in human nasopharyngeal swab specimens using field-effect transistor-based biosensor. ACS Nano 14, 5135-5142 (2020)

69. X. Zhang, Q. Qi, Q. Jing, et al, Electrical probing of COVID-19 spike protein receptor binding domain via a graphene field-effect transistor. arXiv preprint arXiv:2003.12529 (2020)

70. R. Singh, S. Hong, J. Jang, Label-free detection of influenza viruses using a reduced graphene oxide-based electrochemical immunosensor integrated with a microfluidic platform. Sci. Rep. 7, 1-11 (2017)

71. P. Aspermair, V. Mishyn, J. Bintinger, H. Happy, K. Bagga, P. Subramanian, W. Knoll, R. Boukherroub, S. Szunerits, Reduced graphene oxide-based field effect transistors for the detection of 
E7 protein of human papillomavirus in saliva. Anal Bioanal Chem (2020). https://doi.org/10.1007/s00216-020-02879-z

72. H.C. Lai, S.F. Chin, S.C. Pang, M.S. Henry Sum, D. Perera, Carbon nanoparticles based electrochemical biosensor strip for detection of Japanese encephalitis virus. J. Nanomater. 2017, 18 (2017)

73. W.M. Hassen, C. Chaix, A. Abdelghani, F. Bessueille, D. Leonard, N. Jaffrezic-Renault, An impedimetric DNA sensor based on functionalized magnetic nanoparticles for HIV and HBV detection. Sensors Actuators B Chem. 134, 755-760 (2008)

74. N. Alia, O. Sheh, Y.W. Fen, J. Abd, M. Yasmin, Sensitive detection of dengue virus type 2 E-proteins signals using self-assembled monolayers / reduced graphene oxide-PAMAM dendrimer thin film-SPR optical sensor. Sci Rep 10(1), 1-15 (2020)

75. B. Yang, H. Gong, C. Chen, X. Chen, C. Cai, A virus resonance light scattering sensor based on mussel-inspired molecularly imprinted polymers for high sensitive and high selective detection of hepatitis A virus. Biosens. Bioelectron. 87, 679-685 (2017)

76. R. Wang, Y. Li, Hydrogel based QCM aptasensor for detection of avian influenza virus. Biosens. Bioelectron. 42, 148-155 (2013)

77. H. Hoon, H. Jin, H. Kook, J. Hun, H. Soon, J. Sang, Sensors and actuators B : chemical highly sensitive microcantilever biosensors with enhanced sensitivity for detection of human papilloma virus infection. Sensors Actuators B Chem. 221, 1372-1383 (2015)

78. H. Yoo, J. Shin, J. Sim, H. Cho, S. Hong, Biosensors and bioelectronics reusable surface plasmon resonance biosensor chip for the detection of H1N1 influenza virus. Biosens. Bioelectron. 168, $112561(2020)$

79. L.L. Tan, A. Ulianas, L.Y. Heng, N.F. Mazlan, N.D. Jamaluddin, M. Yusof, et al. Sandwich-type DNA micro-optode based on gold-latex spheres label for reflectance dengue virus detection. Sensors 20(7), 1820 (2020)

80. M. Norouzi, M.Z. Ghobadi, M. Golmimi, Quantum dot-based biosensor for the detection of human T-Lymphotropic Virus-1. Anal. Lett. 50, 2402-2411 (2017)

81. K.T. Ramesh, Nanomaterials mechanics and mechanisms. Springer. (2009). https://doi.org/10.1007/978-0-387-09783-1

82. E.R. Banerjee, Nanomaterials and biomedicinetherapeutic and diagnostic approach, First edn. (Springer, Singapore, 2020)

83. B.T. Zhang, X. Zheng, H.F. Li, J.M. Lin, Application of carbonbased nanomaterials in sample preparation: a review. Anal. Chim. Acta 784, 1-17 (2013)

84. P.N. Sudha, K. Sangeetha, K. Vijayalakshmi, A. Barhoum, Nanomaterials history, classification, unique properties, production and market. Emerging Applications of Nanoparticles and Architecture Nanostructures, Elsevier, 2018), p. 341-384

85. N. Celik, W. Balachandran, N. Manivannan, Graphene-based biosensors: methods, analysis and future perspectives. IET Circuits, Devices Syst 9, 434-445 (2015)

86. S. Afsahi, M.B. Lerner, J.M. Goldstein, J. Lee, X. Tang, D.A. Bagarozzi Jr., D. Pan, L. Locascio, A. Walker, F. Barron, B.R. Goldsmith, Novel graphene-based biosensor for early detection of Zika virus infection. Biosens. Bioelectron. 100, 85-88 (2018)

87. J. Wen, W. Li, J. Li, B. Tao, Y. Xu, H. Li, A. Lu, S. Sun, Study on rolling circle amplification of Ebola virus and fluorescence detection based on graphene oxide. Sensors Actuators B Chem. 227, 655-659 (2016)

88. J. Kampeera, P. Pasakon, C. Karuwan, et al., Point-of-care rapid detection of Vibrio parahaemolyticus in seafood using loopmediated isothermal amplification and graphene-based screenprinted electrochemical sensor. Biosens. Bioelectron. 132, 271278 (2019)

89. C. Tancharoen, W. Sukjee, C. Thepparit, T. Jaimipuk, P. Auewarakul, A. Thitithanyanont, C. Sangma, Electrochemical biosensor based on surface imprinting for Zika virus detection in serum. ACS Sensors 4, 69-75 (2019)
90. P.K. Raghav, S. Mohanty, Are graphene and graphene-derived products capable of preventing COVID-19 Infection? Med. Hypotheses 144, 110031 (2020)

91. COVID-19 TESTS | Grapheal. https://www.grapheal.com/covid19. Accessed 9 Sep 2020

92. C. Wang, T. Yao, J. Wu, C. Ma, Z. Fan, Z. Wang, Y. Cheng, Q. Lin, B. Yang, Facile approach in fabricating superhydrophobic and superoleophilic surface for water and oil mixture separation. ACS Appl. Mater. Interfaces 1, 2613-2617 (2009)

93. P. Zhao, N. Li, D. Astruc, State of the art in gold nanoparticle synthesis. Coord. Chem. Rev. 257, 638-665 (2013)

94. J. Narang, N. Malhotra, G. Singh, C.S. Pundir, Electrochemical impediometric detection of anti-HIV drug taking gold nanorods as a sensing interface. Biosens. Bioelectron. 66, 332-337 (2015)

95. Y. Zhou, C.Y. Wang, Y.R. Zhu, Z.Y. Chen, A novel ultraviolet irradiation technique for shape-controlled synthesis of gold nanoparticles at room temperature. Chem. Mater. 11, 2310-2312 (1999)

96. Y. Zhang, W. Chu, A.D. Foroushani, H. Wang, D. Li, J. Liu, C.J. Barrow, X. Wang, W. Yang, New gold nanostructures for sensor applications: a review. Materials (Basel) 7, 5169-5201 (2014)

97. Y. Zhang, J. Qian, D. Wang, Y. Wang, S. He, Multifunctional gold nanorods with ultrahigh stability and tunability for in vivo fluorescence imaging, SERS detection, and photodynamic therapy. Angew Chemie - Int Ed 52, 1148-1151 (2013)

98. Z. Zhang, J. Wang, X. Nie, T. Wen, Y. Ji, X. Wu, Y. Zhao, C. Chen, Near infrared laser-induced targeted cancer therapy using thermoresponsive polymer encapsulated gold nanorods. J. Am. Chem. Soc. 136, 7317-7326 (2014)

99. W. Zhang, F. Wang, Y. Wang, J. Wang, Y. Yu, S. Guo, R. Chen, D. Zhou, $\mathrm{PH}$ and near-infrared light dual-stimuli responsive drug delivery using DNA-conjugated gold nanorods for effective treatment of multidrug resistant cancer cells. J. Control. Release 232, 9-19 (2016)

100. Y.C. Yeh, B. Creran, V.M. Rotello, Gold nanoparticles: Preparation, properties, and applications in bionanotechnology. Nanoscale 4, 1871-1880 (2012)

101. A.M. Youssef, M.S. Abdel-Aziz, S.M. El-Sayed, Chitosan nanocomposite films based on Ag-NP and au-NP biosynthesis by Bacillus Subtilis as packaging materials. Int. J. Biol. Macromol. 69, 185-191 (2014)

102. D. Yin, X. Li, Y. Ma, Z. Liu, Targeted cancer imaging and photothermal therapy via monosaccharide-imprinted gold nanorods. Chem. Commun. 53, 6716-6719 (2017)

103. C.I. Aguirre, E. Reguera, A. Stein, Tunable colors in opals and inverse opal photonic crystals. Adv. Funct. Mater. 20, 2565-2578 (2010)

104. A. Choukourov, H. Biederman, I. Kholodkov, D. Slavinska, M. Trchova, A. Hollander, Properties of amine-containing coatings prepared by plasma polymerization. J. Appl. Polym. Sci. 92, 979-990 (2004)

105. M. Wahle, J. Ebel, D. Wilkes, H.-S. Kitzerow, Asymmetric band gap shift in electrically addressed blue phase photonic crystal fibers. Opt. Express 24, 22718 (2016)

106. S. Schutzmann, I. Venditti, P. Prosposito, M. Casalboni, M.V. Russo, High-energy angle resolved reflection spectroscopy on three-dimensional photonic crystals of self-organized polymeric nanospheres. Opt. Express 16, 897 (2008)

107. O.D. Miller, A.G. Polimeridis, M.T. Homer Reid, C.W. Hsu, B.G. DeLacy, J.D. Joannopoulos, M. Soljačić, S.G. Johnson, Fundamental limits to optical response in absorptive systems. Opt. Express 24, 3329-3364 (2016)

108. E. Lidorikis, S. Egusa, J.D. Joannopoulos, Effective medium properties and photonic crystal superstructures of metallic nanoparticle arrays. J. Appl. Phys. (2007). https://doi.org/10.1063/1. 2709863 
109. J.F. Galisteo-Lõpez, M. Ibisate, R. Sapienza, L.S. Froufe-Pérez, Ú. Blanco, C. Lõpez, Self-assembled photonic structures. Adv. Mater. 23, 30-69 (2011)

110. M. Bardosova, M.E. Pemble, I.M. Povey, R.H. Tredgold, The Langmuir-Blodgett approach to making colloidal photonic crystals from silica spheres. Adv. Mater. 22, 3104-3124 (2010)

111. L. Shi, X. Liu, H. Yin, J. Zi, Optical response of a flat metallic surface coated with a monolayer array of latex spheres. Phys Lett Sect A Gen At Solid State Phys 374, 1059-1062 (2010)

112. X. Yu, L. Shi, D. Han, J. Zi, P.V. Braun, High quality factor metallodielectric hybrid plasmonic-photonic crystals. Adv. Funct. Mater. 20, 1910-1916 (2010)

113. M. López-García, J.F. Galisteo-López, A. Blanco, J. SánchezMarcos, C. López, A. García-Martín, Enhancement and directionality of spontaneous emission in hybrid self-assembled photonicplasmonic crystals. Small 6, 1757-1761 (2010)

114. W. Wang, S.A. Asher, Photochemical incorporation of silver quantum dots in monodisperse silica colloids for photonic crystal applications. J. Am. Chem. Soc. 123, 12528-12535 (2001)

115. Z. Cai, Y.J. Liu, E.S.P. Leong, J. Teng, X. Lu, Highly ordered and gap controllable two-dimensional non-close-packed colloidal crystals and plasmonic-photonic crystals with enhanced optical transmission. J. Mater. Chem. 22, 24668-24675 (2012)

116. B. Ding, M. Bardosova, M.E. Pemble, A.V. Korovin, U. Peschel, S.G. Romanov, Broadband omnidirectional diversion of light in hybrid plasmonic-photonic heterocrystals. Adv. Funct. Mater. 21, 4182-4192 (2011)

117. N. Elahi, M. Kamali, M.H. Baghersad, Recent biomedical applications of gold nanoparticles: a review. Talanta 184, 537-556 (2018)

118. A. Moroz, Three-dimensional complete photonic-band-gap structures in the visible. Phys. Rev. Lett. 83, 5274-5277 (1999)

119. F. Porcaro, L. Carlini, A. Ugolini, D. Visaggio, P. Visca, I. Fratoddi, I. Venditti, C. Meneghini, L. Simonelli, C. Marini, W. Olszewski, N. Ramanan, I. Luisetto, C. Battocchio, Synthesis and structural characterization of silver nanoparticles stabilized with 3mercapto-1-propansulfonate and 1-thioglucose mixed thiols for antibacterial applications. Materials (Basel). 9 (2016). https://doi. org/10.3390/ma9121028

120. P. Prosposito, F. Mochi, E. Ciotta, M. Casalboni, F. De Matteis, I. Venditti, L. Fontana, G. Testa, I. Fratoddi, Hydrophilic silver nanoparticles with tunable optical properties: application for the detection of heavy metals in water. Beilstein J Nanotechnol 7, 1654-1661 (2016)

121. T. Ding, K. Song, K. Clays, C.H. Tung, Fabrication of 3D photonic crystals of ellipsoids: convective self-assembly in magnetic field. Adv. Mater. 21, 1936-1940 (2009)

122. D. Wang, J. Li, C.T. Chan, V. Salgueiriño-Maceira, L.M. LizMarzán, S. Romanov, F. Caruso, Optical properties of nanoparticle-based metallodielectric inverse opals. Small 1, 122130 (2005)

123. H.P.S. Castro, H. Wender, M.A.R.C. Alencar, S.R. Teixeira, J. Dupont, J.M. Hickmann, Third-order nonlinear optical response of colloidal gold nanoparticles prepared by sputtering deposition. J. Appl. Phys. 114, 183104 (2013). https://doi.org/10.1063/1. 4831679

124. R. Ahmed, M.O. Ozen, M.G. Karaaslan, et al., Tunable fanoresonant metasurfaces on a disposable plastic-template for multimodal and multiplex biosensing. Adv. Mater. 32, 1-11 (2020)

125. A. Mataji-Kojouri, M.O. Ozen, M. Shahabadi, F. Inci, U. Demirci, Entangled nanoplasmonic cavities for estimating thickness of surface-adsorbed layers. ACS Nano 14, 8518-8527 (2020). https://doi.org/10.1021/acsnano.0c02797

126. F. Inci, U. Celik, B. Turken, H.Ö. Özer, F.N. Kok, Construction of P-glycoprotein incorporated tethered lipid bilayer membranes. Biochem Biophys Reports 2, 115-122 (2015)
127. F. Inci, C. Filippini, M. Baday, M.O. Ozen, S. Calamak, N.G. Durmus, S. Wang, E. Hanhauser, K.S. Hobbs, F. Juillard, Multitarget, quantitative nanoplasmonic electrical field-enhanced resonating device (NE2RD) for diagnostics. Proc. Natl. Acad. Sci. 112, E4354-E4363 (2015)

128. F. Inci, M.G. Karaaslan, A. Mataji-Kojouri, P.A. Shah, Y. Saylan, Y. Zeng, A. Avadhani, R. Sinclair, D.T.-Y. Lau, U. Demirci, Enhancing the nanoplasmonic signal by a nanoparticle sandwiching strategy to detect viruses. Appl. Mater. Today 20, 100709 (2020)

129. Z. Li, L. Leustean, F. Inci, M. Zheng, U. Demirci, S. Wang, Plasmonic-based platforms for diagnosis of infectious diseases at the point-of-care. Biotechnol. Adv. 37, 107440 (2019)

130. M. Lõpez-García, J.F. Galisteo-Lõpez, Ú. Blanco, C. Lõpez, A. García-Martín, High degree of optical tunability of self-assembled photonic-plasmonic crystals by filling fraction modification. Adv. Funct. Mater. 20, 4338-4343 (2010)

131. F. Yuan, H. Chen, J. Xu, Y. Zhang, Y. Wu, L. Wang, Aptamerbased luminescence energy transfer from near-infrared-to-nearinfrared upconverting nanoparticles to gold nanorods and its application for the detection of thrombin. Chem - A Eur J 20, 28882894 (2014)

132. S.H. Seo, B.M. Kim, A. Joe, H.W. Han, X. Chen, Z. Cheng, E.S. Jang, NIR-light-induced surface-enhanced Raman scattering for detection and photothermal/photodynamic therapy of cancer cells using methylene blue-embedded gold nanorod@SiO2 nanocomposites. Biomaterials 35, 3309-3318 (2014)

133. M.R. Jones, R.J. Macfarlane, A.E. Prigodich, P.C. Patel, C.A. Mirkin, Nanoparticle shape anisotropy dictates the collective behavior of surface-bound ligands. J. Am. Chem. Soc. 133, 1886518869 (2011)

134. Y. Tan, W. Qian, S. Ding, Y. Wang, Gold-nanoparticle-infiltrated polystyrene inverse opals: a three-dimensional platform for generating combined optical properties. Chem. Mater. 18, 3385-3389 (2006)

135. A.Z. Khokhar, F. Rahman, N.P. Johnson, Preparation and properties of gold-infiltrated polystyrene photonic crystals. J. Phys. Chem. Solids 72, 185-189 (2011)

136. Z. Yang, Z. Li, X. Lu, F. He, X. Zhu, Y. Ma, R. He, F. Gao, W. Ni, Y. Yi, Controllable biosynthesis and properties of gold nanoplates using yeast extract. Nano-Micro Lett. (2017). https://doi.org/10. 1007/s40820-016-0102-8

137. Y. Wang, K.C.L. Black, H. Luehmann, W. Li, Y. Zhang, X. Cai, D. Wan, S.Y. Liu, M. Li, P. Kim, Z.Y. Li, L.V. Wang, Y. Liu, Y. Xia, Comparison study of gold nanohexapods, nanorods, and nanocages for photothermal cancer treatment. ACS Nano 7, 2068-2077 (2013)

138. X. Wang, Y. Li, H. Wang, Q. Fu, J. Peng, Y. Wang, J. Du, Y. Zhou, L. Zhan, Gold nanorod-based localized surface plasmon resonance biosensor for sensitive detection of hepatitis B virus in buffer, blood serum and plasma. Biosens. Bioelectron. 26, 404 $410(2010)$

139. S. Wang, X. Zhao, S. Wang, J. Qian, S. He, Biologically inspired polydopamine capped gold nanorods for drug delivery and lightmediated cancer therapy. ACS Appl. Mater. Interfaces 8, 2436824384 (2016)

140. L. Wang, Y. Liu, W. Li, X. Jiang, Y. Ji, X. Wu, L. Xu, Y. Qiu, K. Zhao, T. Wei, Y. Li, Y. Zhao, C. Chen, Selective targeting of gold nanorods at the mitochondria of cancer cells: implications for cancer therapy. Nano Lett. 11, 772-780 (2011)

141. J. Wang, G. Zhu, M. You, E. Song, M.I. Shukoor, K. Zhang, M.B. Altman, Y. Chen, Z. Zhu, C.Z. Huang, W. Tan, Assembly of aptamer switch probes and photosensitizer on gold nanorods for targeted photothermal and photodynamic cancer therapy. ACS Nano 6, 5070-5077 (2012) 
142. B. Wang, J.H. Wang, Q. Liu, H. Huang, M. Chen, K. Li, C. Li, X.F. Yu, P.K. Chu, Rose-bengal-conjugated gold nanorods for invivo photodynamic and photothermal oral cancer therapies. Biomaterials 35, 1954-1966 (2014)

143. E.L.L. Yeo, J.U.J. Cheah, D.J.H. Neo, W.I. Goh, P. Kanchanawong, K.C. Soo, P.S.P. Thong, J.C.Y. Kah, Exploiting the protein corona around gold nanorods for lowdose combined photothermal and photodynamic therapy. J. Mater. Chem. B 5, 254-268 (2017)

144. A.K. Vala, Exploration on green synthesis of gold nanoparticles by a marine-derived fungus Aspergillus sydowii. Environ. Prog. Sustain. Energy 34, 194-197 (2015)

145. J. Turkevich, P.C. Stevenson, J. Hillier, The formation of colloidal gold. J. Phys. Chem. 57, 670-673 (1953)

146. K. Takemura, O. Adegoke, N. Takahashi, T. Kato, T.C. Li, N. Kitamoto, T. Tanaka, T. Suzuki, E.Y. Park, Versatility of a localized surface plasmon resonance-based gold nanoparticle-alloyed quantum dot nanobiosensor for immunofluorescence detection of viruses. Biosens. Bioelectron. 89, 998-1005 (2017)

147. T.R. Shojaei, M.A.M. Salleh, K. Sijam, R.A. Rahim, A. Mohsenifar, R. Safarnejad, M. Tabatabaei, Detection of Citrus tristeza virus by using fluorescence resonance energy transferbased biosensor. Spectrochim Acta - Part A Mol Biomol Spectrosc 169, 216-222 (2016)

148. C. Huang, T. Wen, F.J. Shi, X.Y. Zeng, Y.J. Jiao, Rapid detection of IgM antibodies against the SARS-CoV-2 virus via colloidal gold nanoparticle-based lateral-flow assay. ACS Omega 5, 12550-12556 (2020)

149. L. Wang, Z. Liu, X. Xia, C. Yang, J. Huang, S. Wan, Colorimetric detection of cucumber green mottle mosaic virus using unmodified gold nanoparticles as colorimetric probes. J. Virol. Methods 243, 113-119 (2017)

150. B.S. Chhikara, Current trends in nanomedicine and nanobiotechnology research. J. Mat 4(1), 19-24 (2017)

151. S. Talebian, G.G. Wallace, A. Schroeder, F. Stellacci, J. Conde, Nanotechnology-based disinfectants and sensors for SARS-CoV2. Nat. Nanotechnol. 15, 618-621 (2020)

152. J.R. Choi, Development of point-of-care biosensors for COVID19. Front Chem. 8 (2020). https://doi.org/10.3389/fchem.2020. 00517

153. G. Palestino, I. García-Silva, O. González-Ortega, S. RosalesMendoza, Can nanotechnology help in the fight against COVID19? Expert Rev Anti Infect Ther 18(9), 849-864 (2020)

154. J. Wang, Analytical electrochemistry third edition (Wiley, Hoboken, 2006)

155. M. Thust, M.J. Schöning, J. Vetter, P. Kordos, H. Lüth, A longterm stable penicillin-sensitive potentiometric biosensor with enzyme immobilized by heterobifunctional cross-linking. Anal. Chim. Acta 323, 115-121 (1996)

156. J. Bobacka, A. Ivaska, A. Lewenstam, Potentiometric ion sensors. Chem. Rev. 108, 329-351 (2008)

157. C. Apetrei, I.M. Apetrei, J.A. de Saja, M.L. Rodriguez-Mendez, Carbon paste electrodes made from different carbonaceous materials: application in the study of antioxidants. Sensors 11, 1328$1344(2011)$

158. A.G. Güell, K.E. Meadows, P.V. Dudin, N. Ebejer, J.V. Macpherson, P.R. Unwin, Mapping nanoscale electrochemistry of individual single-walled carbon nanotubes. Nano Lett. 14, 220-224 (2014)

159. D. Du, J. Liu, X. Zhang, X. Cui, Y. Lin, One-step electrochemical deposition of a graphene-ZrO2 nanocomposite: Preparation, characterization and application for detection of organophosphorus agents. J. Mater. Chem. 21, 8032-8037 (2011)

160. J. Yuan, K. Wang, X. Xia, Highly ordered platinum-nanotubule arrays for amperometric glucose sensing. Adv. Funct. Mater. 15, 803-809 (2005)
161. S. Chakraborty, C. Retna Raj, Pt nanoparticle-based highly sensitive platform for the enzyme-free amperometric sensing of $\mathrm{H} 2 \mathrm{O} 2$. Biosens. Bioelectron. 24, 3264-3268 (2009)

162. C. Ming Li, H. Dong, X. Cao, T.J. Luong, X. Zhang, Implantable electrochemical sensors for biomedical and clinical applications: progress, problems, and future possibilities. Curr. Med. Chem. 14, 937-951 (2007)

163. X. Wang, H. Zhang, E. Wang, Z. Han, C. Hu, Phosphomolybdatepolypyrrole composite bulk-modified carbon paste electrode for a hydrogen peroxide amperometric sensor. Mater. Lett. 58, 16611664 (2004)

164. G. Hu, Z. Zhou, Y. Guo, H. Hou, S. Shao, Electrospun rhodium nanoparticle-loaded carbon nanofibers for highly selective amperometric sensing of hydrazine. Electrochem. Commun. 12, 422 $426(2010)$

165. B. Xu, M.L. Ye, Y.X. Yu, W. De Zhang, A highly sensitive hydrogen peroxide amperometric sensor based on $\mathrm{MnO} 2$ modified vertically aligned multiwalled carbon nanotubes. Anal. Chim. Acta 674, 20-26 (2010)

166. R. Gupta, N.K. Chaudhury, Entrapment of biomolecules in sol-gel matrix for applications in biosensors: problems and future prospects. Biosens. Bioelectron. 22, 2387-2399 (2007)

167. H. Ilkhani, S. Farhad, A novel electrochemical DNA biosensor for Ebola virus detection. Anal. Biochem. 557, 151-155 (2018)

168. K.M. Koczula, A. Gallotta, Lateral flow assays. Essays Biochem. 60, 111-120 (2016)

169. G.A. Posthuma-Trumpie, J. Korf, A. Van Amerongen, Lateral flow (immuno)assay: its strengths, weaknesses, opportunities and threats. A literature survey. Anal. Bioanal. Chem. 393, 569 582 (2009)

170. T. Nicol, C. Lefeuvre, O. Serri, A. Pivert, F. Joubaud, V. Dubée, A. Kouatchet, A. Ducancelle, F. Lunel-Fabiani, H. Le GuillouGuillemette, Assessment of SARS-CoV-2 serological tests for the diagnosis of COVID-19 through the evaluation of three immunoassays: Two automated immunoassays (Euroimmun and Abbott) and one rapid lateral flow immunoassay (NG Biotech). J Clin Virol 129, 104511 (2020)

171. IDSA COVID-19 antibody testing primer. Accessed on 13 Oct 2020. https://www.idsociety.org/globalassets/idsa/public-health/ covid-19/idsa-covid-19-antibody-testing-primer.pdf

172. S.K. Vashist, In vitro diagnostic assays for COVID-19: Recent advances and emerging trends. Diagnostics 10(4), 202 (2020)

173. B.G. Andryukov, Six decades of lateral flow immunoassay : from determining metabolic markers to diagnosing COVID-19. AIMS Microbiol. 6(3), 280 (2020)

174. Santiago I (2020) Trends and innovations in biosensors for COVID-19 mass testing. ChemBioChem 1-11

175. N. Ravi, D.L. Cortade, E. Ng, S.X. Wang, Diagnostics for SARSCoV-2 detection: a comprehensive review of the FDA-EUA COVID-19 testing landscape. Biosens. Bioelectron. 165, 112454 (2020)

176. B.D. Grant, C.E. Anderson, J.R. Williford, L.F. Alonzo, V.A. Glukhova, D.S. Boyle, B.H. Weigl, K.P. Nichols, SARS-CoV-2 coronavirus Nucleocapsid antigen-detecting half-strip lateral flow assay toward the development of point of care tests using commercially available reagents. Anal. Chem. 92, 11305-11309 (2020)

177. Z. Chen, Z. Zhang, X. Zhai, Y. Li, L. Lin, H. Zhao, L. Bian, P. Li, L. Yu, Y. Wu, G. Lin, Rapid and sensitive detection of anti-SARSCoV-2 IgG, using lanthanide-doped nanoparticles-based lateral flow immunoassay. Anal. Chem. 92, 7226-7231 (2020)

178. J.L. Wu, W.P. Tseng, C.H. Lin, T.F. Lee, M.Y. Chung, C.H. Huang, S.Y. Chen, P.R. Hsueh, S.C. Chen, Four point-of-care lateral flow immunoassays for diagnosis of COVID-19 and for assessing dynamics of antibody responses to SARS-CoV-2. J Infect 81, 435-442 (2020) 
179. Broughton J, Deng X, Yu G, et al (2020) Rapid detection of 2019 novel coronavirus SARS-CoV-2 using a CRISPR-based DETECTR lateral flow assay. medRxiv Prepr Serv Heal Sci 1-28

180. Z. Li, Y. Yi, X. Luo, N. Xiong, Y. Liu, S. Li, R. Sun, Y. Wang, B. Hu, W. Chen, Y. Zhang, J. Wang, B. Huang, Y. Lin, J. Yang, W. Cai, X. Wang, J. Cheng, Z. Chen, K. Sun, W. Pan, Z. Zhan, L. Chen, F. Ye, Development and clinical application of a rapid IgMIgG combined antibody test for SARS-CoV-2 infection diagnosis. J. Med. Virol. 92, 1518-1524 (2020)

181. S. Tasoglu, H.C. Tekin, F. Inci, S. Knowlton, S. Wang, F. WangJohanning, G. Johanning, D. Colevas, U. Demirci, Advances in nanotechnology and microfluidics for human papillomavirus diagnostics. Proc. IEEE 103, 161-178 (2015)

182. H. Zhu, Z. Fohlerová, J. Pekárek, E. Basova, P. Neužil, Recent advances in lab-on-a-chip technologies for viral diagnosis. Biosens. Bioelectron. 153, 112041 (2020)

183. C. Zhao, X. Liu, A portable paper-based microfluidic platform for multiplexed electrochemical detection of human immunodeficiency virus and hepatitis $C$ virus antibodies in serum. Biomicrofluidics 10, 24119 (2016)

184. K. Yamanaka, M. Saito, K. Kondoh, M.M. Hossain, R. Koketsu, T. Sasaki, N. Nagatani, K. Ikuta, E. Tamiya, Rapid detection for primary screening of influenza A virus: microfluidic RT-PCR chip and electrochemical DNA sensor. Analyst 136, 2064-2068 (2011)

185. E. Iswardy, T.-C. Tsai, I.-F. Cheng, T.-C. Ho, G.C. Perng, H.-C. Chang, A bead-based immunofluorescence-assay on a microfluidic dielectrophoresis platform for rapid dengue virus detection. Biosens. Bioelectron. 95, 174-180 (2017)

186. K. Du, M. Park, A. Griffiths, R. Carrion, J. Patterson, H. Schmidt, R. Mathies, Microfluidic system for detection of viral RNA in blood using a barcode fluorescence reporter and a photocleavable capture probe. Anal. Chem. 89, 12433-12440 (2017)

187. Y. Zhang, Y. Wang, Z. Sosic, L. Zang, S. Bergelson, W. Zhang, Identification of adeno-associated virus capsid proteins using ZipChip CE/MS. Anal. Biochem. 555, 22-25 (2018)

188. H. Kyme, C.T. Lee, Y.T. Kim, J.H. Lee, Self-enzyme chemiluminescence immunoassay capable of rapidly diagnosing the infection of influenza A (H1N1) virus. Talanta 192, 189-196 (2019)

189. K. Liu, H. Xu, Z. Li, G. Wang, A centrifugal chemiluminescence detection platform and its application for nucleic acid virus
(H7N9). 2019 IEEE 4th Optoelectron. Glob. Conf (2019), 140143

190. Rodriguez-Manzano J, Malpartida-Cardenas K, Moser N, et al (2020) A handheld point-of-care system for rapid detection of SARS-CoV-2 in under 20 minutes. medRxiv 2020.06.29.20142349

191. G. Qiu, Z. Gai, Y. Tao, J. Schmitt, G.A. Kullak-Ublick, J. Wang, Dual-functional plasmonic photothermal biosensors for highly accurate severe acute respiratory syndrome coronavirus 2 detection. ACS Nano (2020). https://doi.org/10.1021/acsnano.0c02439

192. F. Tian, C. Liu, J. Deng, Z. Han, L. Zhang, Q. Chen, J. Sun, A fully automated centrifugal microfluidic system for sample-toanswer viral nucleic acid testing. Sci. China Chem. (2020). https://doi.org/10.1007/s11426-020-9800-6

193. P.H. Truong, S. You, S.-H. Ji, G.-M. Jeong, Wearable system for daily activity recognition using inertial and pressure sensors of a smart band and smart shoes. Int J Comput Commun Control 14, 726-742 (2020)

194. C.A. Alexander, L. Wang, Big data analytics in heart attack prediction. J Nurs Care 6, 1168-2167 (2017)

195. D.R. Seshadri, E.V. Davies, E.R. Harlow, J.J. Hsu, S.C. Knighton, T.A. Walker, J.E. Voos, C.K. Drummond, Wearable sensors for COVID-19: a call to action to harness our digital infrastructure for remote patient monitoring and virtual assessments. Front Digit Heal 2, 1-11 (2020)

196. V.K. Singh, H. Chandna, A. Kumar, S. Kumar, EAI endorsed transactions IoT-Q-band : a low cost internet of things based wearable band to detect and track absconding COVID-19 quarantine subjects. (2020). https://doi.org/10.4108/eai.13-7-2018.163997

197. H. Jeong, S. Adv, H. Jeong, J.A. Rogers, S. Xu, Continuous onbody sensing for the COVID-19 pandemic: Gaps and opportunities. Sci Adv 6(36), eabd4794 (2020)

198. News and Views, University College Cork. https://www.ucc.ie/ en/news/covid-19-early-warning-system-shows-encouragingresults.html. Accessed on 18 Sep 2020

199. Tectales (2020) Smart ring detects COVID-19 early. https:// tectales.com/wearables-sensors/smart-ring-detects-covid-19early.html. Accessed on 18 Sep 2020

200. Stojanovic R, Skraba A, Lutovac B (2020) A headset like wearable device to track COVID-19 symptoms. 2020 9th Mediterr Conf Embed Comput MECO 2020 8-11 